Article

\title{
Potential of Supercritical Carbon Dioxide Power Cycles to Reduce the Levelised Cost of Electricity of Contemporary Concentrated Solar Power Plants
}

\author{
Francesco Crespi, David Sánchez * (1), Gonzalo S. Martínez and Tomás Sánchez-Lencero \\ and Francisco Jiménez-Espadafor (1) \\ Department of Energy Engineering, University of Seville, Camino de los Descubrimientos s/n, \\ 41092 Seville, Spain; crespi@us.es (F.C.); gsm@us.es (G.S.M.); tmsl@us.es (T.S.-L.); fcojjea@us.es (F.J-E.) \\ * Correspondence: ds@us.es; Tel.: +34-954-486-488
}

Received: 31 May 2020; Accepted: 15 July 2020; Published: 22 July 2020

Featured Application: Assessment of the potential of supercritical Carbon Dioxide power cycles to reduce the Levelised Cost of Electricity of contemporary Concentrated Solar Power plants, with the aim to benchmark the cost of electricity of the current and next generation Concentrated Solar Power (CSP) technology.

\begin{abstract}
This paper provides an assessment of the expected Levelised Cost of Electricity enabled by Concentrated Solar Power plants based on Supercritical Carbon Dioxide $\left(\mathrm{sCO}_{2}\right)$ technology. A global approach is presented, relying on previous results by the authors in order to ascertain whether these innovative power cycles have the potential to achieve the very low costs of electricity reported in the literature. From a previous thermodynamic analysis of $\mathrm{sCO}_{2}$ cycles, three layouts are shortlisted and their installation costs are compared prior to assessing the corresponding cost of electricity. Amongst them, the Transcritical layout is then discarded due to the virtually impossible implementation in locations with high ambient temperature. The remaining layouts, Allam and Partial Cooling are then modelled and their Levelised Cost of Electricity is calculated for a number of cases and two different locations in North America. Each case is characterised by a different dispatch control scheme and set of financial assumptions. A Concentrated Solar Power plant based on steam turbine technology is also added to the assessment for the sake of comparison. The analysis yields electricity costs varying in the range from 8 to over $11 \mathrm{c} / \mathrm{kWh}$, which is near but definitely not below the $6 \mathrm{c} / \mathrm{kWh}$ target set forth by different administrations. Nevertheless, in spite of the results, a review of the conservative assumptions adopted in the analysis suggests that attaining costs substantially lower than this is very likely. In other words, the results presented in this paper can be taken as an upper limit of the economic performance attainable by Supercritical Carbon Dioxide in Concentrated Solar Power applications.
\end{abstract}

Keywords: LCoE; CSP; supercritical $\mathrm{CO}_{2}$

\section{Introduction}

\subsection{Current Status of Concentrated Solar Power Technology. Expectations Raised by Supercritical} Carbon Dioxide Power Cycles

Supercritical Carbon Dioxide power cycles are currently seen as the technology of choice for next generation Concentrated Solar Power plants to produce Solar Thermal Electricity (STE). They promise higher efficiencies than state-of-the-art Concentrated Solar Power (CSP)-STE facilities based on steam technology, and they are reportedly much more compact thanks to the higher density of the working 
fluid and the simpler layout of the working cycle. Nevertheless, this latter feature, compactness of the power block, does not constitute an essential difference with respect to conventional steam technology, given that the power block contributes a fairly small fraction to the land area occupied by a Concentrated Solar Power plant. On the contrary, the higher efficiency of $\mathrm{sCO}_{2}$ systems (as compared to contemporary technology) reduces the heat input needed for a given power output and thermal energy storage capacity, which translates into a smaller solar field and TES system. This turns out to be crucial for reducing both the footprint and cost of this new generation of CSP-STE systems based on $\mathrm{sCO}_{2}$.

In 2011, the SunShot programme, flagship R\&D instrument of the United States Department of Energy to foster the development of solar power generation, set the objective to reduce the cost of solar electricity to $6 \mathrm{c} / \mathrm{kWh}$ in 2020. This ambitious objective was already achieved in 2017 by photovoltaic technology in large-scale facilities, and it has been superseded by a much more ambitious goal of $3 \dot{c} / \mathrm{kWh}$ in 2030. Unfortunately, whilst PV is now cost-effective and competitive against other renewable and non-renewable technologies, even in smaller domestic applications, it looks like CSP-STE is experiencing more difficulties to meet these objectives with the technology currently available. This is where the cumulative cost reduction potential brought about by $\mathrm{sCO}_{2}$ power cycles in combination with more mature solar field and thermal energy storage technologies, along with the exploitation of economies of scale of the CSP industry, comes in to pave the way for a drastic cost reduction of Solar Thermal Electricity. Figure 1, adapted from the information made public by Solar Energy Technologies Office of the Department of Energy [1], provides this roadmap for CSP-STE technologies.

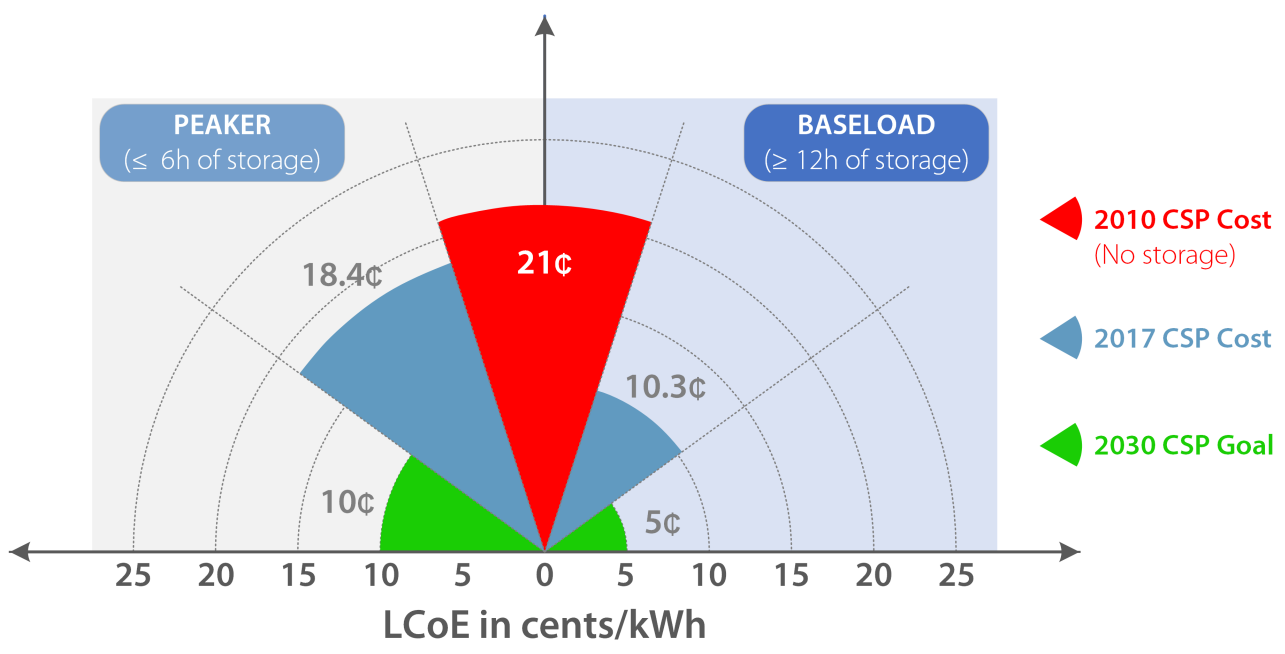

Figure 1. Progress and goals for Solar Thermal Electricity set by the SunShot programme. Data obtained from [1].

\subsection{Technical Hurdles Hindering the Development of Supercritical Carbon Dioxide Power Cycles for} CSP Applications

Unfortunately, even if the advent of supercritical Carbon Dioxide technologies in the beginning of the twenty-first century was seen as the perfect opportunity for a drastic cost reduction of CSP-STE, this perception has not materialised. The large research efforts needed to develop the technology, hence reducing the associated capital cost, and the much slower pace at which CSP is being deployed to the market, are hindering the construction of a first commercial (or even pre-commercial) plant demonstrating the concept. Moreover, in recent years, much more attention has been put on a seemingly unsolvable problem in the low temperature section of the $\mathrm{sCO}_{2}$ cycle, which is the thermodynamic cornerstone of the reportedly better performance of this cycle with respect to conventional steam cycles. 
The realisation of efficient supercritical $\mathrm{CO}_{2}$ power cycles requires that the inlet temperature to the compressor be close to, or even lower than, the critical temperature of this fluid $\left(\approx 31^{\circ} \mathrm{C}\right)$. When this is possible, and if the peak temperature of the cycle is higher than $600-650{ }^{\circ} \mathrm{C}$, then the $\mathrm{sCO}_{2}$ cycle outperforms any Rankine cycle running on water/steam with the same boundary conditions. Unfortunately, CSP plants are typically located in arid sites with ambient temperatures well above $35^{\circ} \mathrm{C}$, which makes it impossible to cool the cycle down to the temperatures needed to compress the fluid in the vicinity of the critical point (there where density is very high) with low power requirements. Accordingly, the rapid transition to an almost ideal behaviour of Carbon Dioxide when temperature increases to $40{ }^{\circ} \mathrm{C}$ or above increases compression work and reduces the thermal efficiency of the power block, which can only be increased again through a large increase of turbine inlet temperature. Of course, this poses new challenges in the area of receiver technology, heat transfer fluids and materials, and also brings about higher costs.

In order to overcome these thermodynamic problems, the SCARABEUS formulates a new conceptual approach to $\mathrm{sCO}_{2}$ cycles whereby the composition of the working fluid is tailored to the high ambient temperatures typically found in CSP sites. This is enabled by the addition of certain dopants with higher critical temperature than Carbon Dioxide to the raw $\mathrm{CO}_{2}$ used in standard $\mathrm{sCO}_{2}$ cycles. The addition of these dopants increases the critical temperature of the mixture and enables liquid-like compression (in supercritical conditions) even at ambient temperatures as high as $40-45^{\circ} \mathrm{C}$ or even $70^{\circ} \mathrm{C}$. The concept has already been formulated by partners of the consortium in [2,3], showing promising results, but it is too early to assess the impact of this new technology on the economic performance of CSP-STE. New equipment (turbomachinery and heat exchangers) is needed and the properties and thermal stability of the dopants considered must be confirmed in long-term operation at high temperature. This falls within the scope of the SCARABEUS project and more information will be presented in the near future.

\subsection{Objectives and Novelty. Benchmarking the First Generation of $\mathrm{CSP}_{-} \mathrm{SCO}_{2}$ Power Plants}

Akin to what was done several years ago to benchmark the then innovative supercritical Carbon Dioxide cycles in Concentrated Solar Power applications, a new reference is now needed to understand whether or not the SCARABEUS technology will eventually yield lower Levelised Cost of Electricity than standard $\mathrm{sCO}_{2}$ power cycles. This encapsulates the twofold objective of the present work, in brief: (i) to produce accurate estimates of the Levelised Cost of Electricity that is attainable for Concentrated Solar Power plants using supercritical $\mathrm{CO}_{2}$ cycles; and (ii) to provide a benchmark for the innovative SCARABEUS technology currently under development.

In this regard, the authors of this paper have carried out an ambitious research to assess the true potential of $\mathrm{sCO}_{2}$ power cycles, with the aim to provide a structured pathway for the thermo-economic feasibility analysis of this technology when applied to CSP power plants. The results of this research have been published regularly in the last four years, and the present paper represents the last, wrap-up piece of the process. The research starts with a very thorough review of the technical (scientific and industrial) works dealing with $\mathrm{sCO}_{2}$ technologies [4]. Since the early works by Sulzer, Angelino and Feher [5-7], this work provides a comprehensive classification of virtually all the cycle layouts found in the literature with the aim to facilitate the comparison between different layouts. Amongst all these cycles, the twelve candidates fitting best into CSP applications are shortlisted for a rigorous and systematic thermodynamic analysis in [8], with the goal to assess their true potential, free from the inherent technical constraints brought about by contemporary technology-related limitations. The thermodynamic assessment presented in [8] is complemented by two additional papers by the authors, $[9,10]$, aimed at assessing the expected component cost of each major equipment in the plant in order to estimate the installation costs of CSP plants using $\mathrm{sCO}_{2}$ power cycles. Out of this analysis, two of the twelve configurations are found to provide the best thermal and economic performance: Allam and Partial Cooling. For these two layouts, dedicated models of performance to assess the 
corresponding off-design performance are developed with the aim to calculate the annual production of electricity (annual yield) for a particular location and set of boundary conditions [11].

With all the information described above, this paper constitutes the last step in this research, leading to the original objective of estimating the Levelised Cost of Electricity $\mathrm{fCSP}-\mathrm{sCO}_{2}$ power plants. As said before, this is the Key Performance Indicator needed to assess whether or not standard $\mathrm{sCO}_{2}$ cycles or the new SCARABEUS concept will enable meeting the ambitious LCoE objective set forth by the SunShot programme. The value of the present paper lies on two main features. First, the wide portfolio of cycle layouts as produced by the review paper written by the authors in 2017 based on 160 references [4], which ensures that all the candidate cycles are included in the comparison. Second, the fact that the series of papers listed in the previous paragraphs are all consistent in the methodologies used and assumptions made. Indeed, each piece of research is built upon a previous one by the authors and, therefore, the thermodynamic references and environmental conditions are all consistent, the time value of money is taken into account to normalise currency, the on and off-design models of performance used to calculate the yield of each cycle are the same, and there is no bias in the comparative analysis of results. This applies to the entire process, from literature review to LCoE calculation.

\section{Techno-Economic Assessment of CSP Based on $\mathrm{sCO}_{2}$}

\subsection{Operating Conditions}

The initial works on supercritical power cycles acknowledged the superior thermal performance of this technology, with respect to standard steam cycles, when turbine inlet temperatures are higher than $600 / 650^{\circ} \mathrm{C}$ [6]. Below this value, the little gain (if any) brought about by $\mathrm{sCO}_{2}$ cycles does not pay off the lower reliability and higher cost of a still less mature technology. Unfortunately, even at the lower end of the temperature range where $\mathrm{sCO}_{2}$ is substantially better than steam, the operating temperatures that are needed are far from the values currently achieved by commercial solar technologies, as recently confirmed by a report issued by the SCARABEUS consortium [12]. Two major hurdles are identified. Receiver technologies able to achieve temperatures in excess of $700{ }^{\circ} \mathrm{C}$ are available but they have not reached the commercial stage yet [13]. This also applies to heat transfer fluids able to harvest this high-temperature thermal energy available in the receiver, in order to feed both the power block and Thermal Energy Storage system, which are currently available but not widely commercialised [14]. This availability of high temperature heat transfer fluids is assessed in Table 1 where the characteristics of different intermediate to high-temperature molten salts are listed. Amongst them, this work makes use of FLiNaK for the sake of continuity with past works by the authors. Thermodynamic-wise, this is a very interesting option even though the very high cost of this salt compromises the economic feasibility of its practical implementation. Still, it is assumed that adopting this fluid yields a safe (conservative) estimate of the cost of electricity associated to this technology.

Table 1. Comparison between different molten salts for intermediate-high temperature Concentrated Solar Power (CSP) plants.

\begin{tabular}{|c|c|c|c|c|c|}
\hline Salt & Composition [\%] & Freezing Point $\left[{ }^{\circ} \mathrm{C}\right]$ & Boiling Point $\left[{ }^{\circ} \mathrm{C}\right]$ & Price $[\$ / k g]$ & Price $\left[\$ / \mathbf{k W h} \mathbf{h}_{t}\right]^{*}$ \\
\hline $\mathrm{NaNO}_{3}-\mathrm{KNO}_{3}$ (Solar Salt) [15] & $60-40$ & 220 & 600 & 0.8 & 10 \\
\hline LiF-NaF-KF (FLiNaK) [14] & $46.5-11.5-42$ & 454 & 1570 & $8.6[16]$ & 54.8 \\
\hline $\mathrm{Li}_{2} \mathrm{CO}_{3}-\mathrm{Na}_{2} \mathrm{CO}_{3}-\mathrm{K}_{2} \mathrm{CO}_{3}$ [17] & $32-33-35$ & 397 & 662 & $2.5[15]$ & 26.1 \\
\hline $\mathrm{Na}_{2} \mathrm{CO}_{3}-\mathrm{NaOH}[17]$ & $19-81$ & 284 & 714 & - & 2.3 \\
\hline $\mathrm{MgCl}_{2}-\mathrm{KCl}[15]$ & $37.5-62.5$ & 426 & 1412 & 0.35 & 5 \\
\hline $\mathrm{ZnCl}-\mathrm{NaCl}-\mathrm{KCl}[15]$ & $69-7-24$ & 204 & 732 & 0.8 & 18 \\
\hline
\end{tabular}

$*$ Values taken from [15] are obtained for $\Delta T_{\text {salt }}=200{ }^{\circ} \mathrm{C}$. For the FLiNaK, authors calculated this price for $\Delta T_{\text {salt }}=290^{\circ} \mathrm{C}$. Values taken from [17] are estimated with market price of raw components in Q1 2015, for a maximum cycle temperature of $6500^{\circ} \mathrm{C}$.

The thermodynamic potential of $\mathrm{sCO}_{2}$ power cycles for different boundary conditions and applications was assessed by the authors in a previous work [8], based on an earlier, thorough 
literature review [4]. In a second step, turbine inlet temperature was set to $750^{\circ} \mathrm{C}$, based on several works in literature $[18,19]$ and on private communications with Abengoa (a SCARABEUS partner), and the assessment of thermal performance was complemented by an economic analysis with the aim to calculate the capital cost of a representative CSP plant using each cycle layout [10]. The main specifications of this reference plant are presented in Table 2.

Table 2. Specifications of the reference $\mathrm{sCO}_{2}$ power plant.

\begin{tabular}{ccccccc}
\hline $\begin{array}{c}\text { Net Power Output } \\
{[\mathrm{MWe}]}\end{array}$ & $\begin{array}{c}\boldsymbol{P}_{\text {max }, \text { sCO }} \\
{[\mathrm{MPa}]}\end{array}$ & $\begin{array}{c}\mathrm{TIT} \\
{\left[{ }^{\circ} \mathrm{C}\right]}\end{array}$ & $\begin{array}{c}\mathrm{TES}_{\text {capacity }} \\
{[\text { hour] }}\end{array}$ & $\begin{array}{c}\mathrm{SM} \\
{[-]}\end{array}$ & $\begin{array}{c}\mathrm{DNI}_{\text {nom }} \\
{\left[\mathbf{W} / \mathbf{m}^{2}\right]}\end{array}$ & $\begin{array}{c}T_{\text {amb,nom }} \\
{\left[{ }^{\circ} \mathbf{C}\right]}\end{array}$ \\
\hline 50 & 30 & 750 & 10 & 2.4 & 850 & 15 \\
\hline
\end{tabular}

The thermo-economic performance of the reference power plant in Table 2 considering different cycle layouts is presented in Figure 2 for a pressure range deemed affordable in the medium term (15 to $40 \mathrm{MPa})$. Akin to the results provided in [8], $\eta_{\text {th }}$ presents an increasing trend with pressure up $35 \mathrm{MPa}$. This is common to all cycles except the Recompression cycle (RC), in which the efficiency peaks a little sooner $(30 \mathrm{MPa})$. On the other hand, the minimum Overnight Capital Cost is found between 30 and $35 \mathrm{MPa}$ for all the cycles considered. Based on this, turbine inlet pressure is set to $30 \mathrm{MPa}$ in the reference CSP plant, since this yields the best compromise between thermodynamic and economic performances and has already been proven to be achievable in similar power technologies such as ultra-supercritical steam turbines [20].

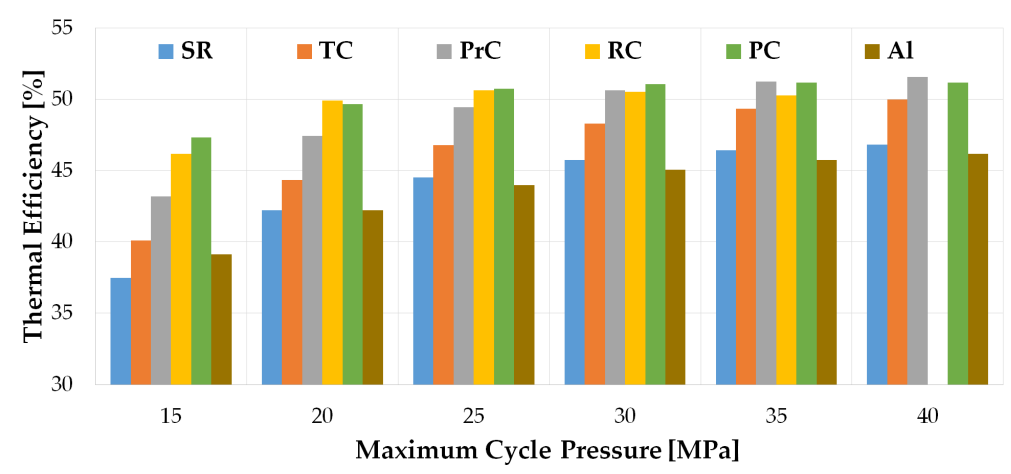

(a) Thermal efficiency.

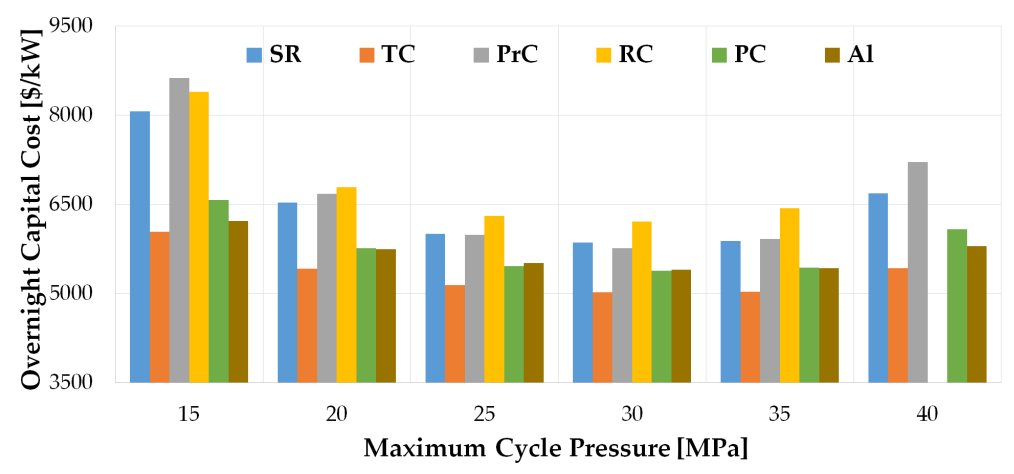

(b) OCC per kilowatt.

Figure 2. Effect of maximum cycle pressure on thermal efficiency and Overnight Capital Cost per kilowatt. Legend: Simple Recuperated (SR), Transcritical (TC), Partial Cooling (PC), Recompression (R), Pre-compression (PrC) and Allam (Al). Data adapted from [10].

\subsection{Economic Assessment}

The calculations presented in Figure $2 b$ above account for uncertainty regarding the capital costs of components. Using a Montecarlo analysis, each component cost is assigned a probability 
density function whereby costs are randomly taken from a given range of values with different probability: the cost of components with a lower maturity are allowed to change in a wider range whereas this range is much narrower for well established technologies. According to these calculations, uncertainty can potentially change the capital cost of the power block by plus/minus one-third of the cost, which is aligned with the information provided in the work by Weiland et al. for the National Energy Technology Laboratory and Sandia National Laboratories in the USA. In this latter work, the authors relied on data provided by Original Equipment Manufacturers to estimate the installation costs of small and large power plants operating on gaseous and solid fossil fuels [21]. The results, which also accounted for uncertainty of the input data provided by vendors, were similar to those reported in [10] both in terms of the total values and the variability brought about by uncertainty. As discussed by Carlson et al., this is very likely due to the lack of a well established market that prevents engineering costs from being charged on very few clients [22].

The data presented in Figure 2 in the previous section are expanded in Table 3, the economic values of which are calculated for the $85 \%$ confidence interval based on the probability density functions discussed in [10]. The table provides information about the main thermodynamic features-thermal efficiency $\left(\eta_{t h}\right)$ and temperature rise across the solar receiver $\left(\Delta T_{\text {solar }}\right)$-and about the Overnight Capital Cost of the plant and the contribution of each major equipment (TES, Solar Field, Tower/Receiver and Power Block). According to these data, the Transcritical $\mathrm{CO}_{2}$ (TC) and Recompression (RC) layouts yield the lowest and highest installation costs, respectively, 5656 and $6867 \$ / k W_{i n s t}$, while the Partial Cooling (PC) cycle seems to provide the best compromise between thermal and economic features, closely followed by the Allam (Al) cycle.

Table 3. Thermo-economic assessment of different cycle layouts. Adapted from [10].

\begin{tabular}{cccccccc}
\hline Cycle & $\begin{array}{c}\eta_{\text {th }} \\
{[\%]}\end{array}$ & $\begin{array}{c}\Delta T_{\text {solar }} \\
{\left[{ }^{\circ} \mathrm{C}\right]}\end{array}$ & $\begin{array}{c}\text { OCC } \\
{\left[\$ / \mathrm{kW}_{\text {inst }}\right]}\end{array}$ & $\begin{array}{c}C_{T E S} \\
{[\mathrm{k} \$]}\end{array}$ & $\begin{array}{c}C_{S F} \\
{[\mathrm{k} \$]}\end{array}$ & $\begin{array}{c}C_{T \& R} \\
{[\mathrm{k} \$]}\end{array}$ & $\begin{array}{c}C_{P B} \\
{[\mathrm{k} \$]}\end{array}$ \\
\hline $\mathrm{SR}$ & 45.8 & 290 & 6404 & 78,184 & 85,657 & 75,123 & 50,585 \\
$\mathrm{TC}$ & 48.3 & 290 & 5656 & 76,648 & 80,675 & 75,307 & 21,896 \\
$\mathrm{PrC}$ & 50.6 & 254 & 6515 & 80,145 & 76,373 & 79,697 & 58,835 \\
$\mathrm{RC}$ & 50.5 & 220 & 6867 & 91,640 & 76,547 & 90,000 & 52,498 \\
$\mathrm{PC}$ & 51.1 & 290 & 5907 & 70,230 & 75,603 & 70,945 & 50,568 \\
$\mathrm{Al}$ & 45.0 & 290 & 5943 & 79,403 & 87,074 & 75,778 & 26,227 \\
\hline
\end{tabular}

The information shown so far confirms that the installation costs based on $\mathrm{sCO}_{2}$ power cycles are comparable or even lower (for some layouts) than for steam turbines used in state-of-the-art CSP plants $-5800 \$ / k W_{\text {inst }}$ according to [23]. The large cost share of the Thermal Energy Storage system is also confirmed, which puts the temperature rise across the solar receiver stems forward as a critical factor involved in plant design, given its very strong impact on the inventory of salts that is needed to operate a plant of given output and storage capacity. Finally, heat exchangers stem as the most relevant individual component in the power block cost-wise, Figure 3, with a larger share than turbomachinery; this confirms earlier comments in this section.

A closer look into the operation of the cycles compared in Table 3 reveals that the Transcritical $\mathrm{CO}_{2}$ cycle requires the most restricting boundary conditions in order to achieve the lowest installation costs in the list. This is due to the need to enable condensation of the working fluid, which is only possible if the inlet temperature to the Transcritical $\mathrm{CO}_{2}$ pump is set to about $15^{\circ} \mathrm{C}$ (strictly speaking, a temperature lower than the critical temperature of $\mathrm{CO}_{2}$ would suffice to enable the implementation of a Transcritical cycle. Nevertheless, performance-wise, this layout only makes sense if the saturation temperature in the condenser is substantially lower than the critical temperature. This is why a value of $15^{\circ} \mathrm{C}$ at the pump inlet is usually adopted). This translates into ambient temperatures in the order of $8{ }^{\circ} \mathrm{C}$ if an evaporative cooling tower is considered or less than $5^{\circ} \mathrm{C}$ if air coolers are used, values that are only rarely found in the arid (even desertic) locations where CSP plants are typically found. The dismissal of the Transcritical $\mathrm{CO}_{2}$ layout for these reasons narrows the selection of cost-effective 
configurations to the Allam and Partial Cooling cycles, the layouts of which are presented in Figure 4 . The main features of these cycles are:

- Allam cycle: it is an extremely high recuperative cycle, an evolution of a standard Brayton cycle incorporating a three-step compression process with two compressors and a pump separated by an intercooler and a condenser respectively. Originally proposed by Allam [24] for oxy-combustion applications, this layout has been adapted considering pure $\mathrm{sCO}_{2}$ as working fluid [8].

- Partial Cooling cycles: this cycle derives directly from Angelino's work [6], and it is an evolution of a Recompression cycle with the addition of a cooler and a pre-compressor before the flow-split. The most interesting features of the Partial Cooling cycle are its high specific work [25] and a very low sensitivity of global efficiency to deviations of pressure ratio from the optimum value [26].

The installation costs reported in Table 3 are presented graphically in Figure 3, showing that the high temperature heat exchanger (heat adder or heater) is the key contributor to installation costs, accounting for approximately half of the total OCC of the power block. This is due to the very high operating pressure and temperature of the $\mathrm{sCO}_{2}-\mathrm{FLiNaK}$ heat exchanger which, as a consequence, requires the utilisation of special alloys like Inconel 617 [10].
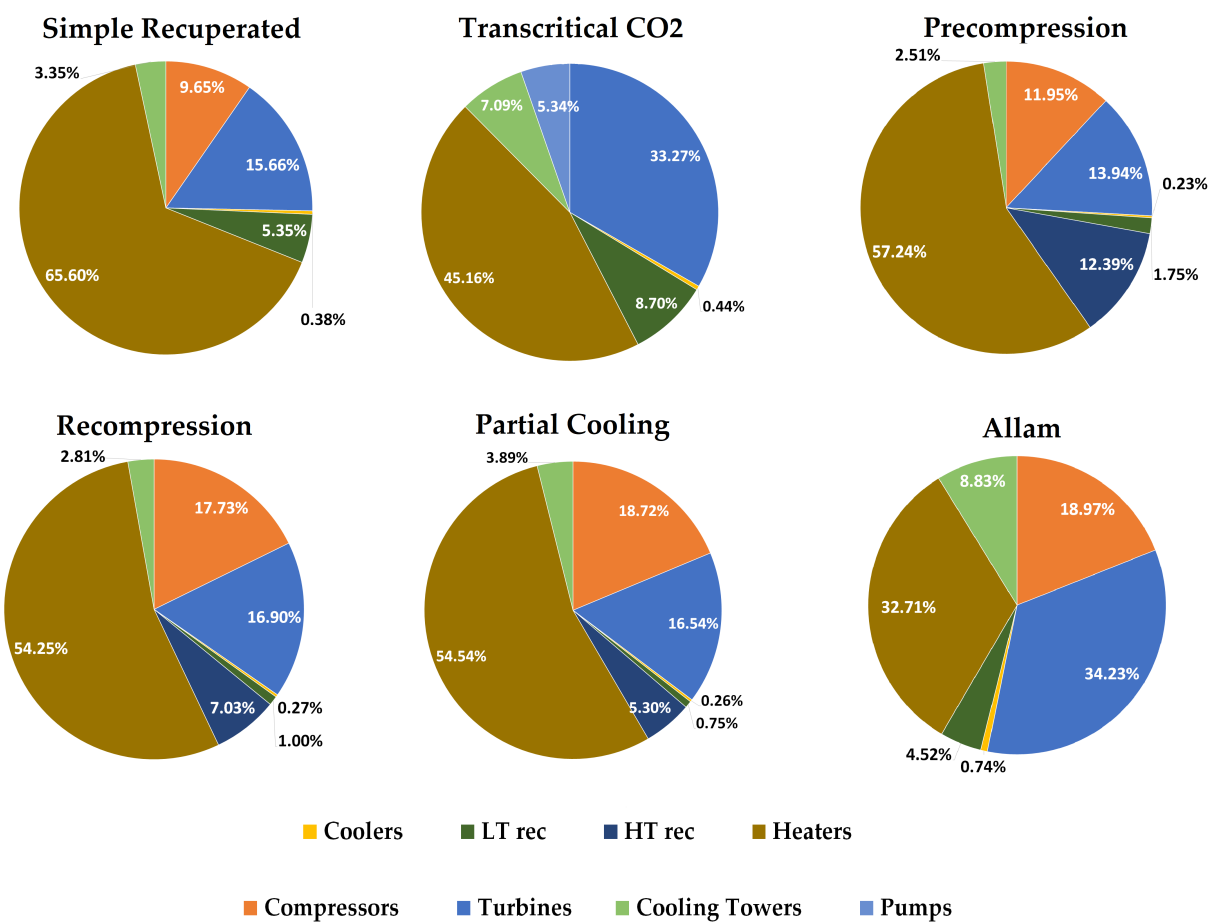

Figure 3. Breakdown of the Overnight Capital Cost of the power block.

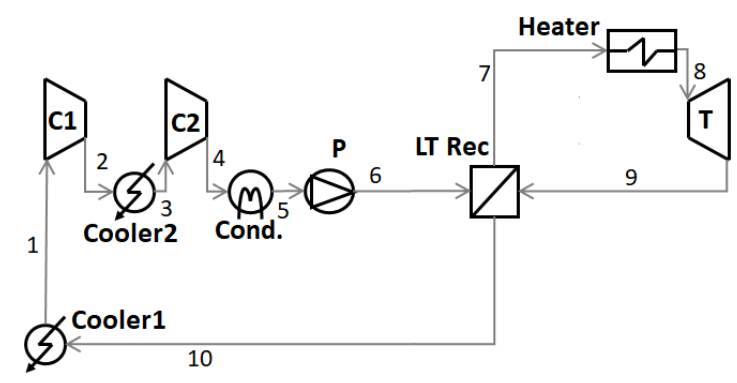

(a) Allam.

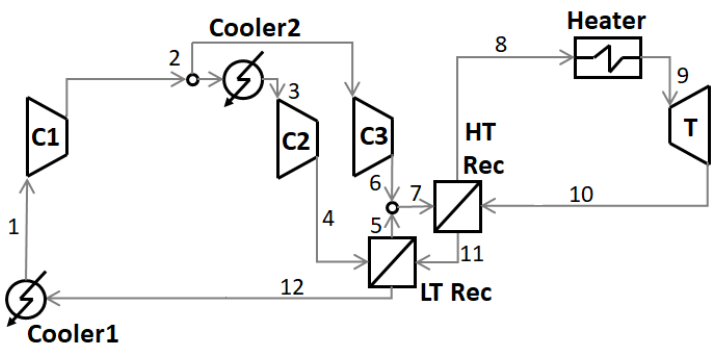

(b) Partial Cooling.

Figure 4. Layouts of the Allam and Partial Cooling cycles. 


\section{Levelised Cost of Electricity of CSP Plants Based on $\mathrm{sCO}_{2}$}

\subsection{Preliminary Notes on the Assessment of the Levelised Cost of Electricity (LCoE)}

In addition to the installation costs presented in earlier sections of this paper, estimating the Levelised Cost of Electricity of CSP plants based on $\mathrm{sCO}_{2}$ technology requires a model to simulate the off-design performance of the power plant throughout the year. This provides the hourly output of the power plant for the specific boundary conditions-ambient temperature and pressure, available solar radiation, as described in [27] and, more recently [11]. The resulting information is then combined with the installation costs to obtain $L C o E$, as discussed in detail by M. Martin [13]. To this end, the authors have relied on the System Advisor Model SAM developed by the National Renewable Energy Laboratory of the United States' Department of Energy, since this is widely accepted by the scientific community and already employed in cost estimation for $\mathrm{sCO}_{2}$ power plants $[28,29]$.

The first part of this section describes the methodology used to incorporate the part-load performance of the Allam and Partial Cooling cycles into SAM's calculation procedure. Then, this information is used to model the reference 50 MW CSP plant in Table 2, considering either of the cycles selected in the previous section. For each one, two different locations and four different combinations of financial parameters and dispatch control models are assessed. Finally, the results obtained are compared against a state-of-the-art CSP plant using a standard power block based on steam turbines.

The input parameters defining the solar field are set to their default values, meaning that the geometry of the field is optimised according to state-of-the-art specifications that are representative of the current industrial practice. The type and composition of the molten salt (or Heat Transfer Fluid considered) is selected in the Tower and Receiver menu, where either commercial solar salts $\left(\mathrm{NaNO}_{3} \mathrm{KNO}_{3}\right)$ or FLiNaK can be selected. The latter is the same molten salt employed by the in-house models developed by the authors and it is therefore selected for this $L C o E$ assessment.

For the power block, SAM is limited to the Recompression layout when it comes to power blocks based on supercritical $\mathrm{CO}_{2}$ systems, which is a strong limitation in this work. This is why the user-defined option is selected, which enables implementing the off-design performance of the Allam and Partial Cooling cycles modelled with the proprietary code developed by the authors and described in [11]. This is the step where the integration between SAM and the authors' in-house codes actually takes place, enabling a much more detailed and flexible assessment of supercritical $\mathrm{CO}_{2}$ cycles than otherwise enabled by SAM. This integration requires the following specific information, in addition to more general technical features like the type of cooling system used (air or water cooled):

- MOD1-Performance as a function of HTF temperature: the part-load performance of the power cycle for variable molten salt (hot) temperature is obtained for three normalised mass flow rates of molten salts, in this case: $0.2,1$ and 1.05. The rated hot temperature of molten salts is set to $770{ }^{\circ} \mathrm{C}$ and this parameter is varied between 700 and $800{ }^{\circ} \mathrm{C}$ in the analysis.

- MOD2-Performance as a function of HTF mass flow rate: the part-load performance of the power cycles for variable mass flow rate of molten salts is obtained for three values of ambient temperature, in this case: 5,15 and $40^{\circ} \mathrm{C}$. To this end, the same range of normalised mass flow rate as in the previous bullet point is considered; i.e., between $20 \%$ and $105 \%$ of the rated mass flow rate of FLiNaK.

- MOD3-Performance as a function of ambient temperature: the part-load performance of the power cycles is obtained when ambient temperature varies between 5 and $40^{\circ} \mathrm{C}$. Again, three molten salt (hot) temperatures are considered: 700,770 and $800^{\circ} \mathrm{C}$.

The MOD-1 to MOD-3 tables corresponding to the reference power plant based on the Allam and Partial Cooling cycles are provided in Appendix A. They contain information about the specific off-design cycle performance considered in the simulations leading to the calculation of the Levelised Cost of Electricity and, therefore, they are deemed very valuable in terms of credibility of the work. The following list clarifies each parameter reported in Appendix A: 
- $\quad$ Net electric output $\left(\dot{W}_{c y c l e}\right)$ : power output at generator terminals minus auxiliary power consumption. Auxiliary power accounts for the power needed to drive auxiliary equipment in the power block.

- Heat input $\left(Q_{i n}\right)$ : heat supplied to the power block (i.e., absorbed by the working fluid).

- Power consumption of the cooling system $\left(\dot{W}_{\text {cooling }}\right)$ : power consumed by the evaporative cooling system.

- Water mass flow rate of the cooling system $\left(\dot{m}_{w, \text { cooling }}\right)$ : total amount of water needed in the cooling system.

These parameters are obtained for the so-called best control strategy and they must be normalised with respect to their rated values. For a more detailed discussion about how the power cycles are operated off-design, interested readers are referred to a complementary work by the authors [11].

\subsection{Dispatch Control and Financial Model}

Dispatch control refers to the scheme under which the Thermal Energy Storage System and power block are operated. In other words, the periods and operating conditions during which the power block drains energy from the Thermal Energy Storage to make up for the lack of concentrated solar energy supplied from the solar field directly (in a power plant using molten salts, heat input to the power block is always provided by the Thermal Energy Storage system. The text refers to situations where the net energy balance in the Thermal Energy Storage systems is negative), in order to achieve the desired turbine output.

Two different dispatch control schemes are considered in this work: the default scheme reported by SAM and the scheme proposed by the SunShot Vision Study [28]. A graphical representation of these is presented in Figure 5 which confirms that these schemes merely define an overall schedule of plant operation but they do not substitute or interfere with the off-design control strategies described in another work from the same authors [11]. Actually, the control schemes are aimed at enabling the output setting assigned by the dispatchability scheme. In particular, for SAM's default dispatch control, the plant runs at full capacity whenever possible, enabling a 5\% over-charge during the central hours of the day in summer time, characterised by the highest solar irradiation. Running the plant in these conditions increases the average output of the plant but this is, potentially, at the cost of fewer operating hours in seasons with fewer sun hours. As opposed to this, the dispatch control scheme adopted by the SunShot Vision case drains energy from the Thermal Energy Storage system to sustain operation at $75 \%$ load during off-sun hours or during the day in seasons with lower solar radiation. This reduced load operation, marked in dark green (also number 2) in Figure 5, enables longer operating hours and reduces the number of shut-down/start-up manoeuvrers throughout the year.

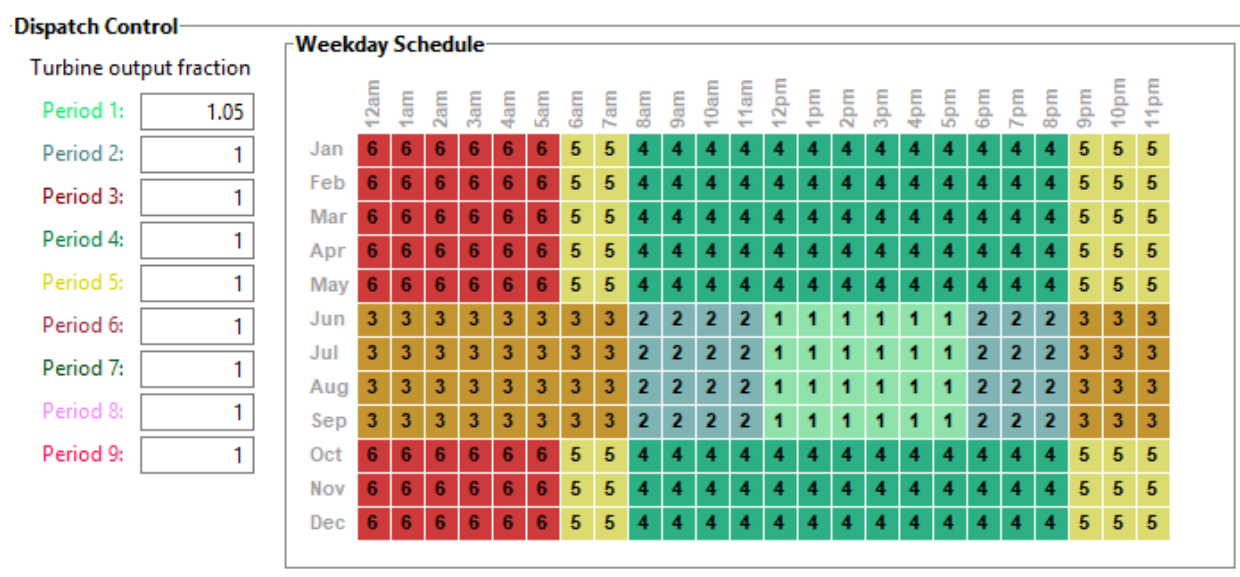

(a)

Figure 5. Cont. 


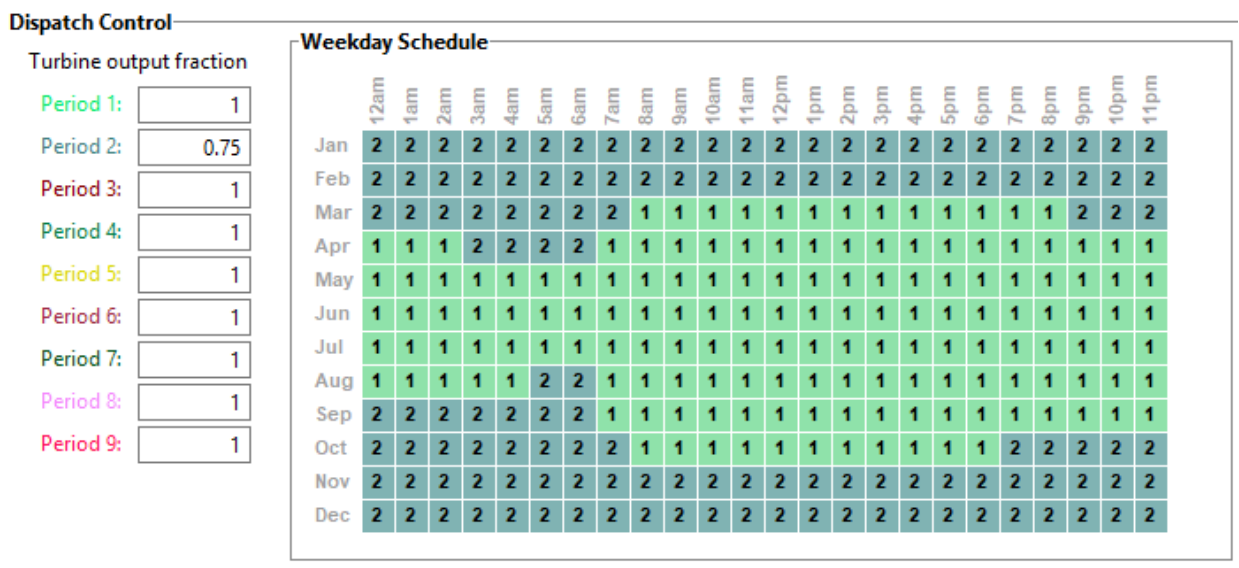

(b)

Figure 5. Different dispatch controls used to assess the Levelised Cost of Electricity. (a) System advisor model's (SAM's) default dispatch control. (b) Dispatch control scheme for the SunShot Vision case [28].

The different sets of financial assumptions adopted by SAM and the SunShot Vision study are listed in Table 4. The information includes the target internal rate of return and time (year) when this should be achieved, lifetime of the project, inflation rate, nominal discount rate (also termed rate of return), debt ratio, payback time and interest rate. These parameters are needed to calculate the corresponding Power Purchase Agreement (PPA) required to meet the target IRR according to the remaining financial settings. This $P P A$ is actually another difference between the financial models based on SAM's and Sunshot cases, in particular regarding the Time-of-delivery factors (TOD) shown in Figure 6 and Table 5 which are multiplied by the PPA bid price to calculate the energy price in the corresponding hour. These TODs are therefore correction factors to take into account the variable sales price of electricity ( $P P A)$ throughout the day.
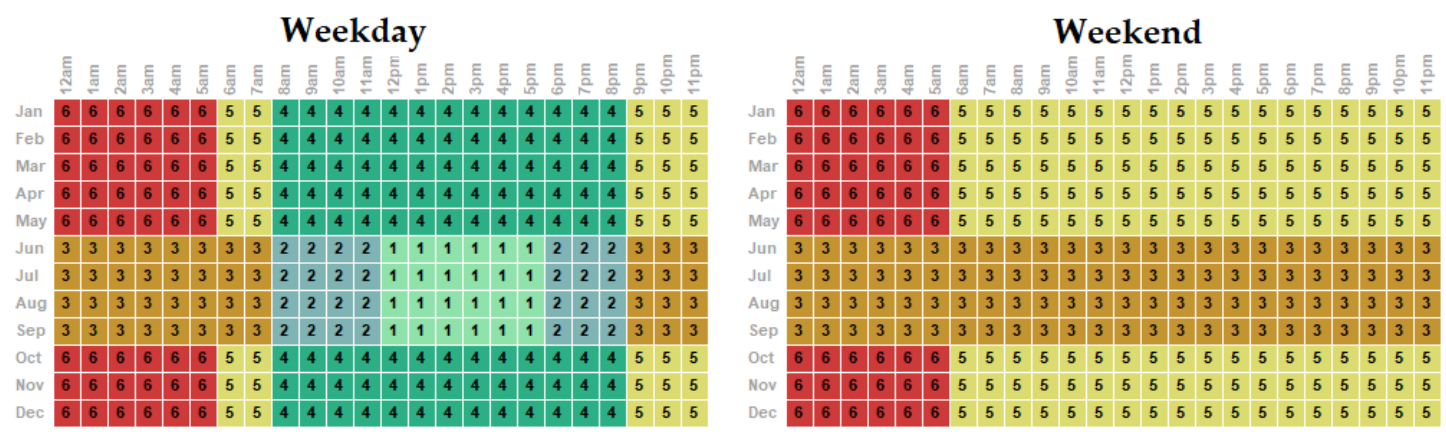

(a)
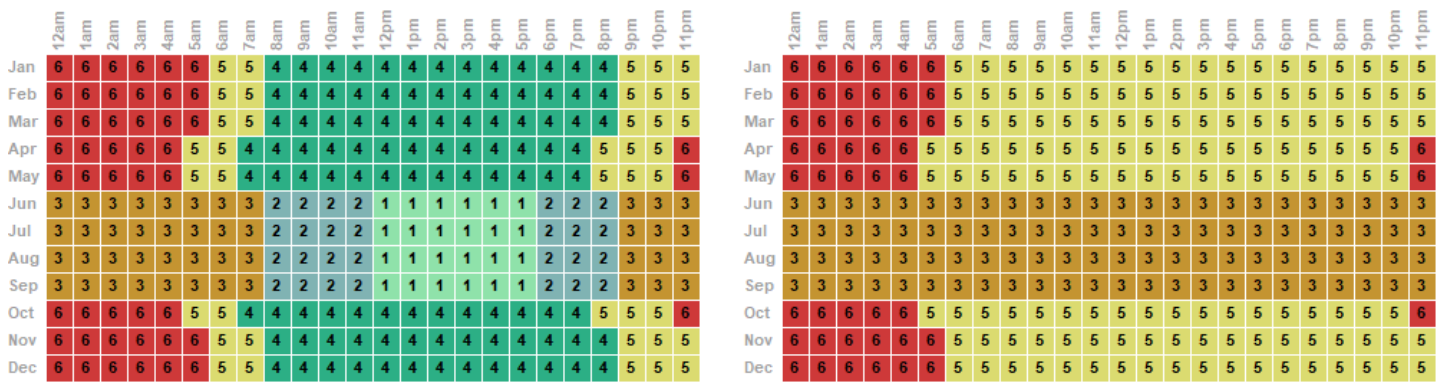

(b)

Figure 6. Different Time-of-Delivery factors used to assess the Levelised Cost of Electricity. (a) SAM's default Time-of-Delivery factors. (b) Delivery factors of the SunShot Vision Study case [28]. 
Table 4. Financial parameters employed in the SAM's default and SunShot Vision cases. The parameters that are not reported here are set to the values used by SAM's default model in Table 6.

\begin{tabular}{lcc}
\hline & SAM Default & SunShot Vision Study \\
\hline IRR target [\%] & 11 & 15 \\
IRR target Year & 20 & 30 \\
Analysis period [years] & 25 & 35 \\
Inflation rate [\%] & 2.5 & 3 \\
Nominal Discount rate [\%] & 8.14 & 8.66 \\
Loan Percent of total capital cost [\%] & 50 & 60 \\
Loan Duration [years] & 18 & 15 \\
Loan Annual interest rate [\%] & 7 & 7.1 \\
\hline
\end{tabular}

Table 5. Different Time-of-Delivery factors employed by SAM's Default and SunShot Vision Study's financial models.

\begin{tabular}{ccccccc}
\hline Financial Model & Period 1 & Period 2 & Period 3 & Period 4 & Period 5 & Period 6 \\
\hline SAM Default & 2.064 & 1.2 & 1 & 1.1 & 0.8 & 0.7 \\
SunShot Vision Study & 3.28 & 1.28 & 0.67 & 1.02 & 0.82 & 0.65 \\
\hline
\end{tabular}

The combination of dispatchability and financial schemes described in this section yields the four cases listed in Table 6. These are studied in the next section to check the associated Levelised Cost of Electricity.

Table 6. Cases showing different combinations of Dispatch Control and Financial Models.

\begin{tabular}{lcc}
\hline Case No. & Financial Model & Dispatch Control \\
\hline Case 1 & Default SAM & Default SAM \\
Case 2 & Default SAM & SunShot Vision Study \\
Case 3 & SunShot Vision Study & Default SAM \\
Case 4 & SunShot Vision Study & SunShot Vision Study \\
\hline
\end{tabular}

\subsection{Overall Analysis of the Levelised Cost of Electricity}

The results obtained for the three CSP power plants described before, and for the four possible cases, are presented in Figures 7 and 8 for two reference locations in North America: Las Vegas and Tonopah (NV). These two locations are selected for their vicinity to existing Concentrated Solar Power plants using either collector technology, parabolic trough and central receiver, including the then first-of-a-kind Crescent Dunes project which made use of tower technology and an impressive Thermal Energy Storage system enabling operation at full capacity for ten hours. Five figures of merit are taken into account, spanning across the thermal and financial features of the plant:

- Thermal performance:

- Yield $\left(E_{\text {year }}\right),[G W h]$ : this is the annual production of electricity of the power plant.

- Capacity Factor $(C F)$, [\%]: ratio from the system's annual production of electricity in the first year of operation to the theoretical energy production, should the system run at the rated capacity throughout the entire year. This is a measure of the electricity that the system would be able to produce if it were operated at its nominal capacity for every hour of the year, and it can be significantly affected by the plant location and by the operation (dispatch control) of the Thermal Energy Storage system.

- Financial:

- Levelised Cost of Electricity $L C o E[c / \mathrm{kWh}]$ : a measure of the total project life cycle costs relative to the total production of energy throughout the entire project lifetime. 
- $\quad$ Net Present Value NPV [\$]: discounted (present) value of the net cash inflow.

- Internal Rate of Return IRR, [\%]: the nominal discount rate that would yield null NPV for given economic and financial assumptions (including the sales price of electricity specified in the Power Purchase Agreement-PPA.

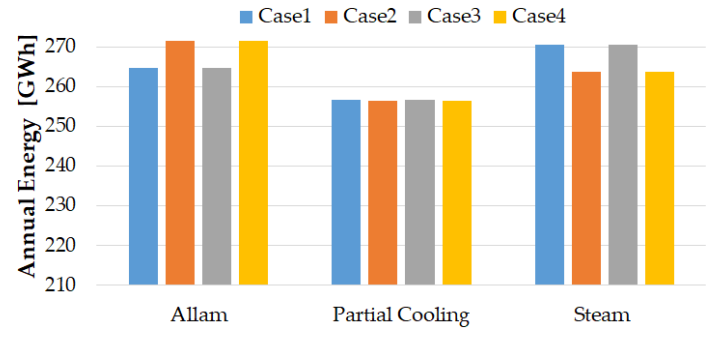

(a) Annual yield of year 1, Las Vegas (NV).

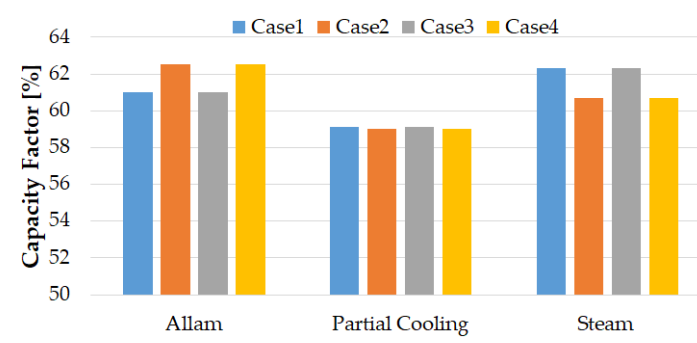

(c) Capacity factor for a CSP located in Las Vegas (NV).

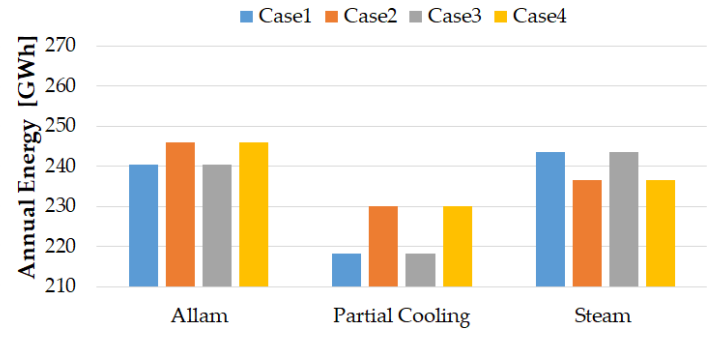

(b) Annual yield of year 1, Tonopah (NV).

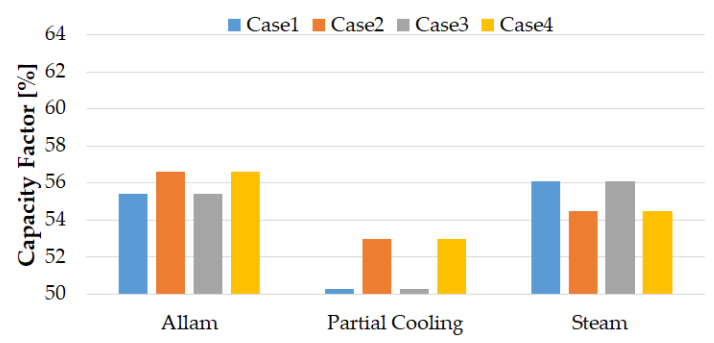

(d) Capacity Factor for a CSP located in Tonopah (NV).

Figure 7. Annual yield and capacity factor for the three power cycles and two locations considered. Designation of cases is explained in Table 6.

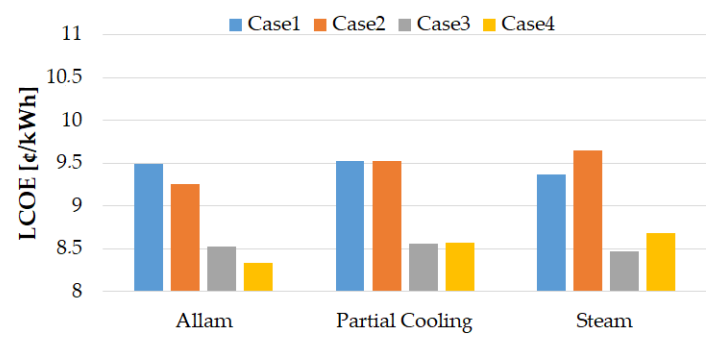

(a) Levelised Cost of Electricity for a CSP located in Las Vegas (NV).

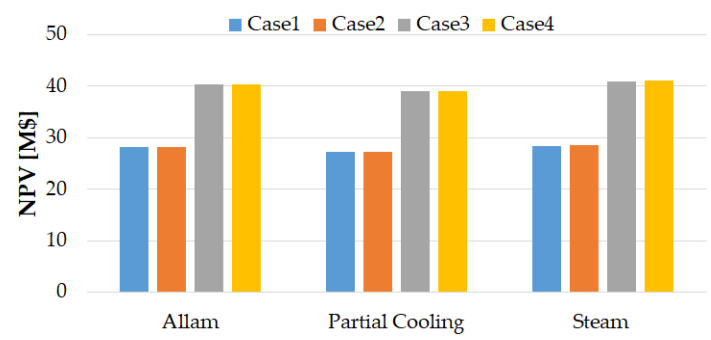

(c) Net Present Value of a CSP located in Las Vegas (NV).

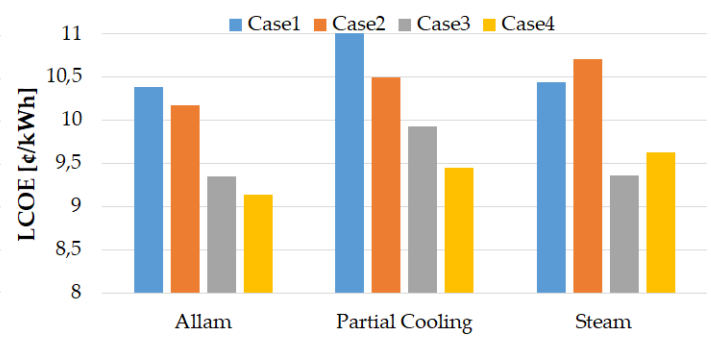

(b) Levelised Cost of Electricity for a CSP located in Tonopah (NV).

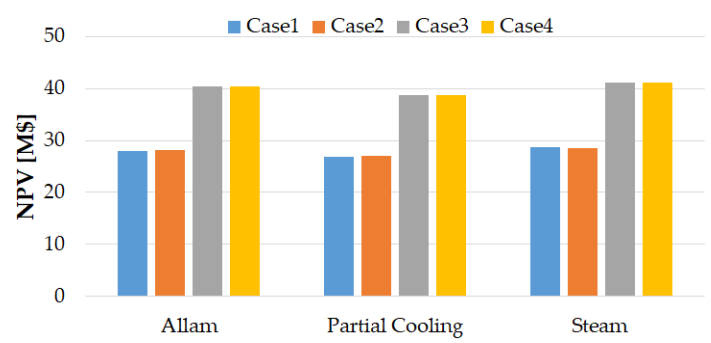

(d) Net Present Value of a CSP located in Tonopah (NV).

Figure 8. Levelised Cost of Electricity and Net Present Value of the three different cycles and four combinations of financial/dispatch control settings. Two locations in Nevada are considered: Las Vegas and Tonopah. 
Several observations are worthwhile in Figure 7. The location of a CSP plant is expected to have a very strong impact on the annual yield. This is to be expected and is confirmed here by the larger production of electricity of the plant in Las Vegas.

Another interesting aspect, which is not as evident, is the impact of the dispatch control scheme, which yields a very variable plant performance pattern. For supercritical Carbon Dioxide plants based on the Allam cycle, the dispatch control proposed in SAM by default (Cases 1 and 3) is able to produce $5 \mathrm{GWh}$ /year more energy than that proposed in the SunShot Vision Study. In order to find the reasons for this, it is reminded that the latter scheme was based on lower power settings to extend the operating time of the plant in periods with expectedly low solar availability, as opposed to the scheme proposed by SAM where power generation is maximised regardless of a potentially higher number of start-ups. The superior performance of this approach will have to be compared against the economic impact of the latter on maintenance costs in an actual power plant. Alas, as expected, the higher yield of Cases 1 and 3 in both locations translate into higher capacity factors.

Interestingly, the impact of dispatch control on plant performance for a conventional CSP plant based on a steam cycle is exactly the opposite. The dispatch control proposed in the SunShot Vision Study produces a higher yield than the default control proposed by SAM. The margin between the two is again in the order of $5 \mathrm{GWh} /$ year, and the reasons for this are found in the off-design performance of the steam cycle, and to make it even more interesting, for a CSP plant using $\mathrm{sCO}_{2}$ technology based on the Partial Cooling cycle, the annual production of electricity seems to be totally insensitive to the dispatchability scheme adopted, as shown in Figure 7. The patterns discussed are applicable to both locations, which supports their dependence on the characteristics of the power block and not on the boundary conditions of the power block. All this opens a very interesting research pathway incorporating the combined optimisation of both cycle technology, cycle layout and dispatch control scheme.

From a quantitative standpoint, the foregoing qualitative considerations translate as follows, for the cases considered. A CSP plant based on the Allam cycle in Las Vegas achieves 10\% higher yield and capacity factor than if it were located in Tonopah and the difference would increase to about $12.5 \%$ if a Partial Cooling $\mathrm{sCO}_{2}$ or a steam cycle were used. Regarding dispatch control, the SunShot Vision Study setting yields 3\% higher $E_{y e a r}$ and CF when using the Allam cycle whereas a 3\% drop in these parameters must be expected when considering a steam-turbine CSP plant. Further to the discussion in the previous paragraph, this can also be explained by the fact that SAM's Default and SunShot Vision Study's dispatch control modes are specifically designed for steam and $\mathrm{sCO}_{2}$ power cycles respectively.

The same capacity to significantly change the results is not observed when assessing the two sets of financial assumptions. The input parameters considered in the SunShot Vision Study always lead to better financial results than SAM's, yielding higher NPV and lower LCOE for a given location, as shown in Figure 8. This is mostly due to the longer lifetime and higher IRR considered, even if the former model presents a larger debt fraction, set to $60 \%$ (versus 50\% for SAM's default case) of the total capital cost. It is also observed that $N P V$ depends on the financial model given the minor deviations seen between different locations, cycles or dispatch control systems. On the other hand, $L C o E$ happens to be strongly affected by all the factors considered so far. In particular:

- Las Vegas yields lower $L C o E$, even if some $L C o E$ s obtained with the SunShot Vision Study case considering the Allam cycle in Tonopah are comparable to those obtained by the SAM setting in Las Vegas, regardless of the cycle used.

- The trend followed by $L C O E$ is approximately symmetrical to the figures of merit indexing thermal performance ( $C F$ and $E_{y e a r}$ ) and balanced by the financial model. Higher $C F$ usually comes with lower $L C o E$ but, if the two options with the lowest $C F$ are considered-Partial Cooling cycle located in Tonopah for Cases 1 and 2-it is found that Case 1 always yields the highest $L C o E$ whereas the SunShot model can compensate for the $C F$ effect in Case 3. 
- If the same financial model is considered (Cases 1-2, Cases 3-4), the lowest LCoEs are achieved by plants presenting better performance metrics (higher $C F$ and $E_{y e a r}$ ), as observed in Figures $7 \mathrm{a}, \mathrm{b}$ and $8 \mathrm{a}, \mathrm{b}$. Based on this foreseeable result, increasing the capacity factor of a plant (and therefore its annual yield) is confirmed to be of capital importance to increase the feasibility of $\mathrm{sCO}_{2}$-based CSP plants.

Based on the foregoing results, it is difficult to ascertain the best power cycle, given that the three power cycles yield very similar $L C o E$ in the order of $8.5-9.5 \mathrm{c} / \mathrm{kWh}$, see Figure $8 \mathrm{a}, \mathrm{b}$. Moreover, the small differences observed lie within the cumulative uncertainty incurred by all the assumptions made throughout the analysis.

Figure 9 presents the final comparison of $L C O E$ for the reference plant using the power cycles considered. The length of each bar comes determined by the values taken by LCoE for the different cases considered in Table 6 . The lowest cost of electricity is obtained for the best combination of the Allam cycle $(8.33 \mathrm{c} / \mathrm{kWh})$, while the worst case based on the Partial Cooling cycle yields the highest $L C O E(11.02 \mathrm{c} / \mathrm{kWh})$. Interestingly, the range of $L C O E$ for plants based on steam turbine technology falls entirely within the values covered by the other cycles. This confirms the lack of a clear, unambiguous conclusion about the optimum CSP plant concept stemming from this work, as suggested in the introductory section of the paper. To the authors' opinion, however, this result does confirm the large potential of $\mathrm{sCO}_{2}$ power cycles for CSP applications, which must be considered as a solid alternative to the standard steam Rankine cycle approach in spite of the apparently marginal gain suggested by Figure 9. Such a strong statement is based on the fact that, even if the results obtained are still far from the $6 \mathrm{c} / \mathrm{kWh}$ target set by the SunShot programme (or $3 \mathrm{c} / \mathrm{kWh}$ in the longer term), it must not be forgotten that the $L C o E$ values presented in this paper for $\mathrm{sCO}_{2}$ are estimates based on deliberately conservative assumptions. For instance, the utilisation of molten salts that are less costly than FLiNaK, which is a reasonable assumption for an actual power plant in the future, would certainly cut down installation costs and, therefore, $L C O E$ by a large fraction given the dominant role of the Thermal Energy Storage System in determining the economic performance of the plant. This is a very likely possibility in the near future which would cut $\mathrm{LCoE}$ down for the $\mathrm{sCO}_{2}$ cases in Figure 9 but would not affect the cost of the steam-based case. Therefore, it may as well be the case that mid-term CSP plants employing Allam and Partial Cooling cycles are able to achieve LCoEs lower than those obtained in this research, and closer to the SunShot objective, once the very strong economies of scale that are characteristic of CSP start impacting $\mathrm{sCO}_{2}$ power blocks. There is no reason why a cost decline similar to that experienced by conventional CSP-STE plants cannot be experienced by this new technology in the near term.

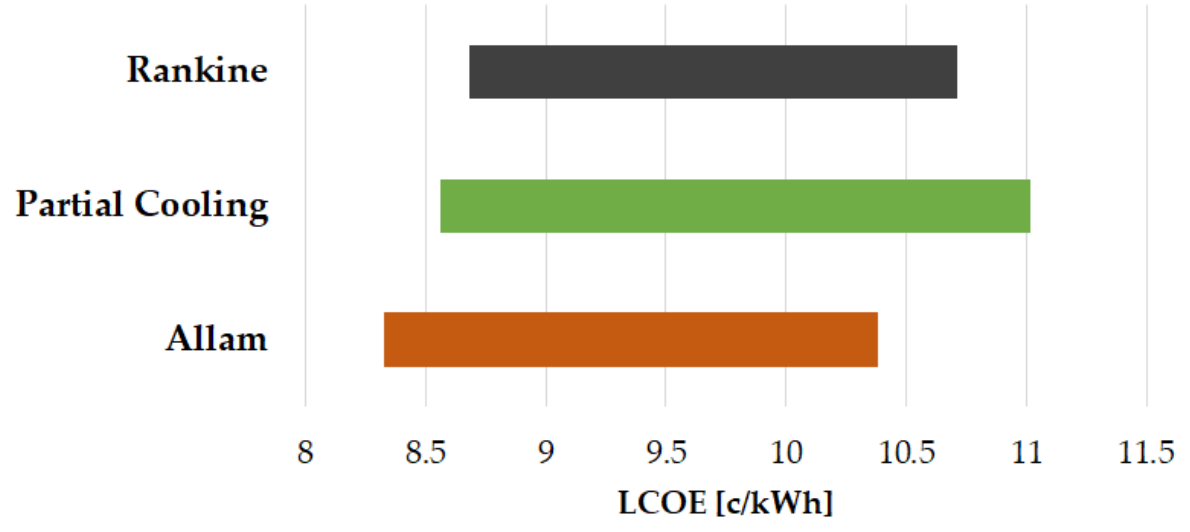

Figure 9. Range of Levelised Cost of Energy ( $L C o E)$ for CSP plants based on different power cycles.

With this in mind, it is concluded that more accurate part-load models and integration schemes in SAM or equivalent software will prove that either the Allam or Partial Cooling cycle layouts have the potential to make a strong case for the next generation of CSP plants based on $\mathrm{sCO}_{2}$ power cycles, 
enabling the ambitious objectives targeted by the SunShot Program. In this regard, it is interesting to see how the selection of a particular set of assumptions (both financial, economic and thermal) has the potential to turn the Recompression cycle into a competitive option to achieve the $6 \mathrm{c} / \mathrm{kWh}$ target of the SunShot programme [28], which is certainly in contrast with the conclusions obtained in this work. Far from discussing the credibility of other research works, the latter statement aims to highlight that much more work on the assessment of appropriate sets of non-technical boundary conditions is still required.

\section{Some Considerations about Uncertainty}

Assessing a trustworthy and thorough feasibility analysis of CSP plants employing $\mathrm{sCO}_{2}$ power blocks is very challenging, mostly due to the low TRL and MRL of $\mathrm{sCO}_{2}$ technology and to the scarcity of reliable cost-related information. To overcome this limitation, this work is based on a series of assumptions, in order to reduce the complexity of the problem down to a manageable level. In this section, these assumptions are revisited with the aim to assess the reliability of the results, highlighting both the positive features and also the main flaws.

There are two types of uncertainty when exploring the potential of disruptive technologies: avoidable and unavoidable. Avoidable uncertainty that is incurred in the simulation of processes due to the lack of precise information about the operating conditions and specifications of certain components. The same applies to the calculation of capital and operating costs of a technology that is not commercially available yet. As far as this work is concerned, previous publications by the authors have justified the simplifying assumptions made to carry out the thermal assessment $[8,11]$ and to estimate the capital costs of $\mathrm{sCO}_{2}$ technology $[9,10]$. In this former case, the performance results have been validated against results in literature and also against experimental data [30]. For capital costs, given the lack of mass production of the equipment needed $\left(\mathrm{sCO}_{2}\right.$ compressors, expanders and heat exchangers and also high pressure and temperature solar receivers), a dedicated Monte Carlo- based uncertainty quantification analysis is incorporated in the calculations. In either case, uncertainty can be classified as avoidable inasmuch as the continuous development of the technology and, later, the deployment of a commercial plant will expectedly yield more accurate technical and economic information.

The financial boundary conditions set to calculate the Levelised Cost of Electricity of the technology is affected by the so-called unavoidable uncertainty. Future economic scenarios are not foreseeable and, more often than not, previsions are drastically altered by unpredictable political and/or social changes; the twenty-first century is still in its infancy and it has already seen several of these crises. As a consequence of this, setting the discount rate turns out an uncertain process that includes thorough considerations about how investments in a particular market might unfold in the future. The same applies to other local assumptions related to foreseen energy policies and subsidies, especially in unstable regions of the world [31]. These aspects involved in the economic valuation of constructing innovative CSP plants are inherently uncertain and, therefore, cannot be removed from the analysis completely.

With all this in mind, the results obtained are deemed as trustworthy as possible for a technology that is still far from the marketplace. Moreover, as reported in the concluding remark of the previous section, the results obtained are thought to provide a very solid upper limit of the expected LCoE enabled by $\mathrm{sCO}_{2}$ power cycles in CSP applications. From here, future works will continuously reduce avoidable uncertainty to values comparable to those reported for state-of-the-art CSP plants based on steam turbines.

\section{Conclusions}

This paper is focused on the assessment of the Levelised Costs of Electricity that should be expected if supercritical $\mathrm{CO}_{2}$ power cycles were adopted in next generation Concentrated Solar Power plants for Solar Thermal Electricity generation. A simulation platform developed by the authors for the techno-economic analysis of Concentrated Solar Power plants has been integrated with the 
Solar Advisor Model to produce a larger simulation tool enabling the assessment of technical and non-technical plant characteristics to a level of detail not enabled by the latter software alone.

Plants based on steam turbine technology and on $\mathrm{sCO}_{2}$ cycles have been analysed under different financial/economic boundary conditions and for two different locations which can be regarded as above-average for CSP installations. In all cases, the net output of the plant is $50 \mathrm{MW}$ and the Thermal Energy Storage system is sized to enable operation at full capacity for ten hours. In the most favourable cases, the Partial Cooling and Allam cycles provide an $L C o E$ of $8.56 \mathrm{c} / \mathrm{kWh}$ and 8.33 c/kWh respectively, along with a Capacity Factor of around $59 \%$ and $62.5 \%$. On the contrary, in the worst case, the $L C O E$ of the Partial Cooling cycle increases to $11 \mathrm{c} / \mathrm{kWh}$, with a $C F$ slightly higher than $50 \%$, while the values of the Allam cycle are $10.38 \mathrm{c} / \mathrm{kWh}$ and $55.4 \%$ respectively.

When these figures of merit are compared with a reference plant based on a state-of-the-art steam Rankine cycle, the main finding is that both $\mathrm{sCO}_{2}$ cycles have the potential to yield $L C o E s$ comparable to those of the reference plant, or even lower. Taking into account the conservative approach employed throughout the present work, especially in terms of installation costs, this comes to confirm that $\mathrm{sCO}_{2}$ power cycles are an interesting alternative to enhance the competitiveness of CSP-STE plants in the mid to long term, even if the drastic cost reductions claimed by some authors seem not to be so straightforward in the short term. In the longer term, mass deployment and a further refinement of the technology (technology/cost-wise) will very likely increase the economic gains of CSP-sCO $\mathrm{Cl}_{2}$ plants but, at the moment, this remains yet to be verified.

In this regard, it is worth highlighting the groundbreaking concept proposed by the SCARABEUS project, funded by the European Commission and running from 2019 to 2023. In this project, $\mathrm{CO}_{2}$ is doped with certain compounds to modify the critical properties of the resulting mixture, shifting the critical temperature to higher values and enabling the practical implementation of condensing $\mathrm{sCO}_{2}$ cycles (for instance, the Transcritical $\mathrm{CO}_{2}$ cycle would be realisable even at very high ambient temperatures). Substituting these new $\mathrm{CO}_{2}$ mixtures for pure $\mathrm{CO}_{2}$ in the same layouts would, in turn, boost the efficiency of the resulting power plant, which translates into a smaller footprint of the solar field and also smaller size of the Thermal Energy Storage system. If these were eventually possible, as already suggested by the preliminary results in [3], the resulting power plant would easily reduce the LCoE reported in this paper by a large margin, possibly achieving the ambitious targets set forth by the SunShot programme.

Author Contributions: Conceptualization, D.S. and T. S.-L.; formal analysis, G.S.M.; funding acquisition, D.S.; investigation, F.C.; methodology, F.C., D.S. and F.J. J.-E.; software, F.C., G.S.M. and F.J.J.-E.; supervision, T.S.-L.; validation, T.S.-L. and F.J.J.-E.; writing-original draft, F.C.; writing-review and editing, D.S. and T.S.-L. All authors have read and agreed to the published version of the manuscript.

Funding: The SCARABEUS project has received funding from the European Union's Horizon 2020 research and innovation programme under grant agreement $\mathrm{N}^{\circ} 814985$.

Acknowledgments: SoftInWay is gratefully acknowledged for supporting the simulation of turbomachinery performance maps for supercritical $\mathrm{CO}_{2}$ applications.

Conflicts of Interest: The authors declare no conflict of interest.

\title{
Abbreviations
}

The following abbreviations are used in this manuscript:

\author{
LCoE Levelised Cost of Energy \\ CSP Concentrated Solar Power \\ PV Photovoltaic \\ $\mathrm{sCO}_{2} \quad$ Supercritical $\mathrm{CO}_{2}$ \\ USD US Dollar \\ TES Thermal Energy Storage \\ HTF Heat Transfer Fluid \\ TIT Turbine Inlet Temperature
}




$\begin{array}{ll}\text { SR } & \text { Simple Recuperated cycle } \\ \text { TC } & \text { Transcritical CO2 cycle } \\ \text { PrC } & \text { Precompression cycle } \\ \text { RC } & \text { Recompression CO2 cycle } \\ \text { Al } & \text { Allam cycle } \\ \text { PC } & \text { Partial Cooling cycle } \\ \text { OCC } & \text { Overnight Capital Cost } \\ \text { SM } & \text { Solar Multiple } \\ \text { DNI } & \text { Direct Normal Irradiance } \\ \Delta T_{\text {solar }} & \text { Temperature rise across solar receiver } \\ \text { SF } & \text { Solar Field } \\ \text { T\&R } & \text { Tower and Receiver } \\ \text { PB } & \text { Power Block } \\ \text { LT Rec } & \text { Low-temperature receiver } \\ \text { HT Rec } & \text { High-temperature receiver } \\ \text { RMB } & \text { Chinese Renminbi } \\ \text { SAM } & \text { System Advisor model } \\ \dot{W}_{\text {cycle }} & \text { Power Cycle Net Electric Output } \\ Q_{\text {in }} & \text { Heat Input to Power Cycle } \\ \dot{W}_{\text {cooling }} & \text { Cooling System Power Consumption } \\ \dot{m}_{w, \text { cooling }} & \text { Cooling System Water Mass Flow Rate }\end{array}$

\section{Appendix A. Integrating the Off-Design Performance of the Power Block into the System Advisor Model}

Table A1. Performance as a function of HTF temperature (MOD1) table for Allam cycle. "Low", "On” and "High" respectively refer to the three normalised mass flow employed: $0.2,1$ and 1.05.

\begin{tabular}{|c|c|c|c|c|c|c|c|c|c|c|c|c|}
\hline$T_{H T F}$ & $\dot{\mathbf{W}}_{\text {cycle,low }}$ & $\dot{\mathbf{W}}_{\text {cycle,on }}$ & $\dot{W}_{\text {cycle,high }}$ & $Q_{\text {in,low }}$ & $Q_{i n, o n}$ & $Q_{i n, h i g h}$ & $\dot{W}_{\text {cooling,low }}$ & $\dot{\mathbf{W}}_{\text {cooling,on }}$ & $\dot{W}_{\text {cooling,high }}$ & $\dot{m}_{w, \text { cooling,low }}$ & $\dot{m}_{w, \text { coolingon }}$ & $\dot{m}_{w, \text { cooling,high }}$ \\
\hline 700 & 0.13153 & 0.71357 & 0.77024 & 0.15189 & 0.75096 & 0.80142 & 0.051941 & 0.78613 & 0.93529 & 0.15189 & 0.75096 & 0.80142 \\
\hline 705 & 0.13729 & 0.75097 & 0.78691 & 0.15541 & 0.77679 & 0.81566 & 0.056937 & 0.93796 & 0.94818 & 0.15541 & 0.77679 & 0.81566 \\
\hline 707.5 & 0.13933 & 0.76061 & 0.79881 & 0.15708 & 0.78553 & 0.82476 & 0.057959 & 0.94214 & 0.95883 & 0.15708 & 0.78553 & 0.82476 \\
\hline 712.5 & 0.1452 & 0.77963 & 0.81809 & 0.1606 & 0.80278 & 0.84288 & 0.06362 & 0.95214 & 0.96625 & 0.1606 & 0.80278 & 0.84288 \\
\hline 715 & 0.14687 & 0.78942 & 0.82727 & 0.1623 & 0.81163 & 0.85203 & 0.06362 & 0.95657 & 0.96844 & 0.1623 & 0.81163 & 0.85203 \\
\hline 717.5 & 0.14862 & 0.79871 & 0.83717 & 0.164 & 0.82002 & 0.86097 & 0.06362 & 0.96154 & 0.97291 & 0.164 & 0.82002 & 0.86097 \\
\hline 720 & 0.1532 & 0.80834 & 0.84642 & 0.16577 & 0.82868 & 0.87006 & 0.07148 & 0.96511 & 0.97536 & 0.16577 & 0.82868 & 0.87006 \\
\hline 727.5 & 0.1587 & 0.83734 & 0.87799 & 0.17078 & 0.85477 & 0.89726 & 0.072099 & 0.97444 & 0.98243 & 0.17078 & 0.85477 & 0.89726 \\
\hline 730 & 0.16376 & 0.84674 & 0.88763 & 0.17264 & 0.8634 & 0.90657 & 0.084065 & 0.97719 & 0.98462 & 0.17264 & 0.8634 & 0.90657 \\
\hline 732.5 & 0.16541 & 0.85598 & 0.897 & 0.17436 & 0.87206 & 0.91542 & 0.084065 & 0.97948 & 0.9869 & 0.17436 & 0.87206 & 0.91542 \\
\hline 735 & 0.16721 & 0.86541 & 0.90685 & 0.17612 & 0.8807 & 0.92472 & 0.084065 & 0.98199 & 0.98892 & 0.17612 & 0.8807 & 0.92472 \\
\hline 737.5 & 0.17044 & 0.87466 & 0.91619 & 0.17786 & 0.88933 & 0.93353 & 0.086255 & 0.98376 & 0.99081 & 0.17786 & 0.88933 & 0.93353 \\
\hline 740 & 0.17475 & 0.88398 & 0.92624 & 0.17954 & 0.89795 & 0.94289 & 0.099483 & 0.98644 & 0.99231 & 0.17954 & 0.89795 & 0.94289 \\
\hline 742.5 & 0.17609 & 0.8926 & 0.93621 & 0.18126 & 0.90633 & 0.95194 & 0.099483 & 0.98747 & 0.99356 & 0.18126 & 0.90633 & 0.95194 \\
\hline 757.5 & 0.18853 & 0.9503 & 0.98962 & 0.19166 & 0.95825 & 1.0064 & 0.26095 & 0.9973 & 1.0055 & 0.19166 & 0.95825 & 1.0064 \\
\hline 760 & 0.19122 & 0.96005 & 1.0051 & 0.19338 & 0.96687 & 1.015 & 0.26826 & 0.99824 & 1.0108 & 0.19338 & 0.96687 & 1.015 \\
\hline 762.5 & 0.19333 & 0.96973 & 1.0153 & 0.19509 & 0.97547 & 1.0242 & 0.26849 & 0.99911 & 1.0135 & 0.19509 & 0.97547 & 1.0242 \\
\hline 765 & 0.19544 & 0.97942 & 1.0254 & 0.19682 & 0.98412 & 1.0333 & 0.26861 & 0.99979 & 1.0156 & 0.19682 & 0.98412 & 1.0333 \\
\hline 767.5 & 0.19694 & 0.98921 & 1.0356 & 0.19775 & 0.99273 & 1.0423 & 0.26884 & 1.0002 & 1.0177 & 0.19775 & 0.99273 & 1.0423 \\
\hline 770 & 0.19793 & 1 & 1.0457 & 0.19837 & 1 & 1.0514 & 0.26884 & 1 & 1.0199 & 0.19837 & 1 & 1.0514 \\
\hline 772.5 & 0.20412 & 1.0072 & 1.0559 & 0.20198 & 1.0098 & 1.0605 & 0.28955 & 1.0085 & 1.022 & 0.20198 & 1.0098 & 1.0605 \\
\hline 775 & 0.20611 & 1.0174 & 1.0661 & 0.20374 & 1.0188 & 1.0695 & 0.2897 & 1.0111 & 1.024 & 0.20374 & 1.0188 & 1.0695 \\
\hline 777.5 & 0.20803 & 1.0268 & 1.0763 & 0.20546 & 1.0273 & 1.0786 & 0.28983 & 1.0135 & 1.0259 & 0.20546 & 1.0273 & 1.0786 \\
\hline 780 & 0.20896 & 1.0369 & 1.0865 & 0.20633 & 1.0361 & 1.0876 & 0.28968 & 1.0154 & 1.0278 & 0.20633 & 1.0361 & 1.0876 \\
\hline 782.5 & 0.21399 & 1.0462 & 1.0968 & 0.20895 & 1.0445 & 1.0967 & 0.29744 & 1.0174 & 1.0295 & 0.20895 & 1.0445 & 1.0967 \\
\hline 785 & 0.21598 & 1.0564 & 1.107 & 0.21066 & 1.0534 & 1.1057 & 0.29761 & 1.0186 & 1.0312 & 0.21066 & 1.0534 & 1.1057 \\
\hline 787.5 & 0.21795 & 1.0657 & 1.1173 & 0.21235 & 1.0618 & 1.1148 & 0.30158 & 1.0198 & 1.0322 & 0.21235 & 1.0618 & 1.1148 \\
\hline 790 & 0.22012 & 1.0759 & 1.1275 & 0.21412 & 1.0706 & 1.1239 & 0.30168 & 1.0208 & 1.0327 & 0.21412 & 1.0706 & 1.1239 \\
\hline 792.5 & 0.2219 & 1.0851 & 1.1378 & 0.21584 & 1.0789 & 1.133 & 0.30599 & 1.0218 & 1.0331 & 0.21584 & 1.0789 & 1.133 \\
\hline
\end{tabular}


Table A2. Performance as a function of HTF mass flow rate (MOD2) table for Allam cycle. "Low", "On" and "High" respectively refer to the three values of ambient temperature employed: 5,15 and $40{ }^{\circ} \mathrm{C}$.

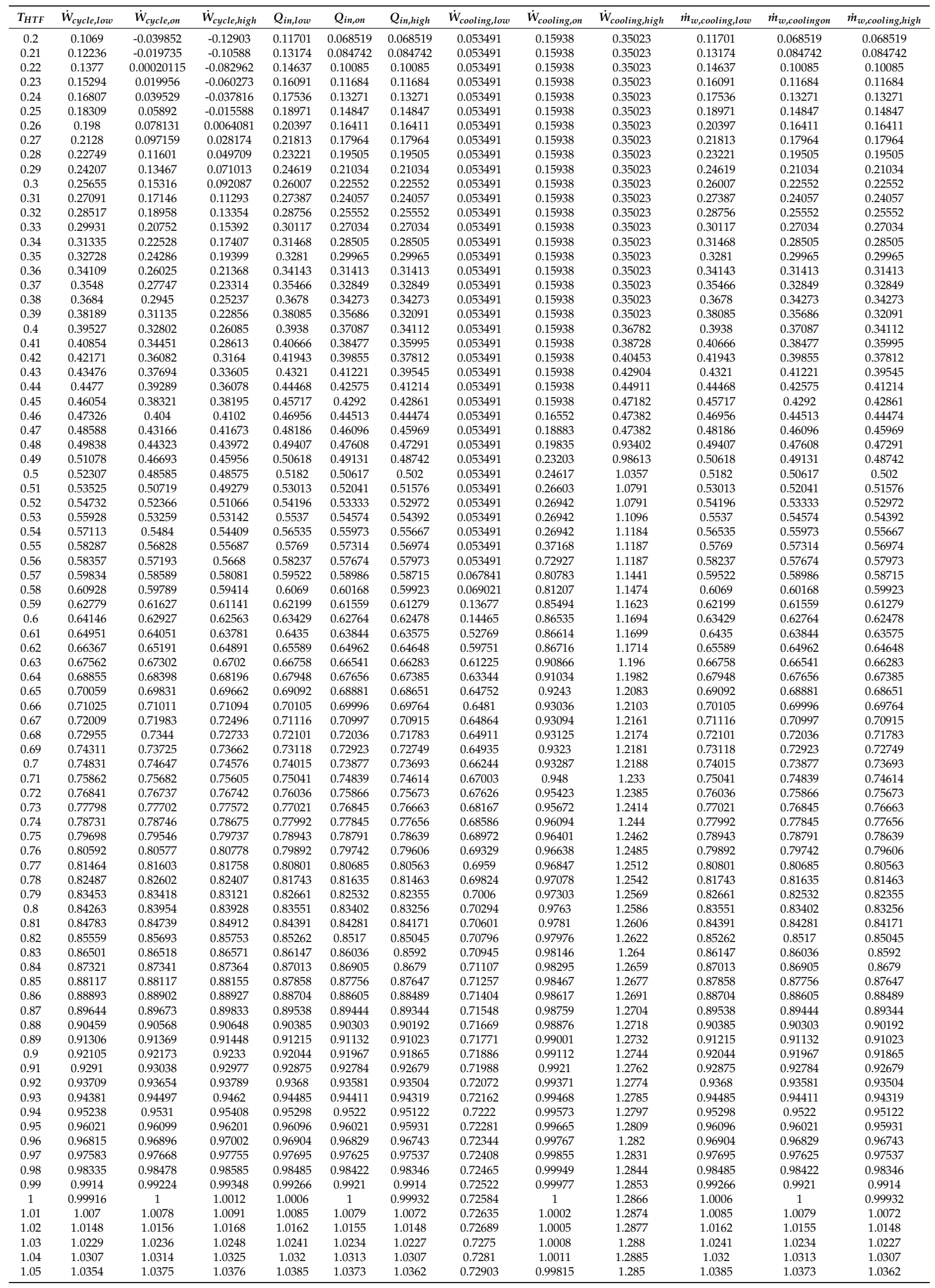


Table A3. Performance as a function of ambient temperature (MOD3) table for Allam cycle. "Low", "On" and "High" respectively refer to the three values of molten salt (hot) temperature levels employed: 700,770 and $800^{\circ} \mathrm{C}$.

\begin{tabular}{|c|c|c|c|c|c|c|c|c|c|c|c|c|}
\hline$T_{H T F}$ & $\dot{W}_{c y c l e, l o w}$ & $\dot{\mathbf{W}}_{\text {cycle,on }}$ & $\dot{\mathbf{W}}_{\text {cycle,high }}$ & $Q_{\text {in,low }}$ & $Q_{i n, o n}$ & $Q_{i n, h i g h}$ & $\dot{W}_{\text {cooling,low }}$ & $\dot{\mathbf{W}}_{\text {cooling,on }}$ & $\dot{W}_{\text {cooling,high }}$ & $\dot{m}_{w, \text { cooling,low }}$ & $\dot{m}_{w, \text { coolingon }}$ & $\dot{m}_{w, \text { cooling, high }}$ \\
\hline 5 & 0.84245 & 1.0002 & 1.0628 & 0.88637 & 1.0012 & 1.043 & 0.68615 & 0.74597 & 0.74426 & 0.88637 & 1.0012 & 1.043 \\
\hline 7.5 & 0.83769 & 0.9998 & 1.0619 & 0.88303 & 1.0008 & 1.0421 & 0.74811 & 0.81131 & 0.80918 & 0.88303 & 1.0008 & 1.0421 \\
\hline 8.75 & 0.83705 & 0.9998 & 1.062 & 0.88206 & 1.0007 & 1.042 & 0.78135 & 0.84512 & 0.84393 & 0.88206 & 1.0007 & 1.042 \\
\hline 11.25 & 0.8369 & 0.99975 & 1.0621 & 0.8813 & 1.0004 & 1.0417 & 0.85157 & 0.90983 & 0.91013 & 0.8813 & 1.0004 & 1.0417 \\
\hline 12.5 & 0.83557 & 0.99978 & 1.0623 & 0.87985 & 1.0003 & 1.0415 & 0.88103 & 0.94082 & 0.94183 & 0.87985 & 1.0003 & 1.0415 \\
\hline 13.75 & 0.83665 & 0.99988 & 1.0624 & 0.88065 & 1.0001 & 1.0414 & 0.91711 & 0.97077 & 0.9726 & 0.88065 & 1.0001 & 1.0414 \\
\hline 15 & 0.83593 & 1 & 1.0625 & 0.87967 & 1 & 1.0413 & 0.94527 & 1 & 1.0024 & 0.87967 & 1 & 1.0413 \\
\hline 18.75 & 0.83564 & 1.0005 & 1.0627 & 0.87829 & 0.99971 & 1.0409 & 1.0302 & 1.082 & 1.0862 & 0.87829 & 0.99971 & 1.0409 \\
\hline 20 & 0.83525 & 1.0005 & 1.0628 & 0.87776 & 0.99956 & 1.0408 & 1.0565 & 1.1075 & 1.1123 & 0.87776 & 0.99956 & 1.0408 \\
\hline 21.25 & 0.83548 & 1.0006 & 1.0628 & 0.87766 & 0.9995 & 1.0407 & 1.0826 & 1.132 & 1.1373 & 0.87766 & 0.9995 & 1.0407 \\
\hline 22.5 & 0.83418 & 1.0006 & 1.0629 & 0.87642 & 0.99937 & 1.0406 & 1.1056 & 1.1555 & 1.1613 & 0.87642 & 0.99937 & 1.0406 \\
\hline 23.75 & 0.83608 & 1.0006 & 1.0629 & 0.87786 & 0.99931 & 1.0405 & 1.1325 & 1.1781 & 1.1843 & 0.87786 & 0.99931 & 1.0405 \\
\hline 25 & 0.83561 & 1.0007 & 1.0629 & 0.87716 & 0.99918 & 1.0404 & 1.1531 & 1.1995 & 1.2063 & 0.87716 & 0.99918 & 1.0404 \\
\hline 26.25 & 0.83268 & 1.0008 & 1.063 & 0.87546 & 0.99912 & 1.0404 & 1.1731 & 1.2198 & 1.2271 & 0.87546 & 0.99912 & 1.0404 \\
\hline 34 & 0.83332 & 1.001 & 1.0631 & 0.8724 & 0.99871 & 1.0399 & 1.2711 & 1.3176 & 1.327 & 0.8724 & 0.99871 & 1.0399 \\
\hline 35 & 0.8366 & 1.0009 & 1.0631 & 0.87816 & 0.99863 & 1.0399 & 1.294 & 1.3261 & 1.3357 & 0.87816 & 0.99863 & 1.0399 \\
\hline 36 & 0.82669 & 1.001 & 1.0632 & 0.86695 & 0.99861 & 1.0398 & 1.2829 & 1.3333 & 1.3431 & 0.86695 & 0.99861 & 1.0398 \\
\hline 37 & 0.84971 & 1.001 & 1.0632 & 0.88567 & 0.99859 & 1.0398 & 1.3101 & 1.3394 & 1.3493 & 0.88567 & 0.99859 & 1.0398 \\
\hline 38 & 0.73357 & 1.001 & 1.0632 & 0.82624 & 0.99858 & 1.0398 & 1.2548 & 1.3444 & 1.3544 & 0.82624 & 0.99858 & 1.0398 \\
\hline 39 & 0.78815 & 1.001 & 1.0632 & 0.84161 & 0.99856 & 1.0398 & 1.2454 & 1.3479 & 1.358 & 0.84161 & 0.99856 & 1.0398 \\
\hline 40 & 0.71604 & 1.001 & 1.0632 & 0.82091 & 0.99857 & 1.0398 & 0.83365 & 1.35 & 1.3601 & 0.82091 & 0.99857 & 1.0398 \\
\hline
\end{tabular}

Table A4. Performance as a function of HTF temperature (MOD1) table for Partial Cooling cycle. "Low", "On" and "High" respectively refer to the three normalised mass flows employed: 0.2, 1 and 1.05 .

\begin{tabular}{|c|c|c|c|c|c|c|c|c|c|c|c|c|}
\hline$T_{\text {HTF }}$ & $\dot{\mathbf{W}}_{c y c l e, l o w}$ & $\dot{W}_{c y c l e, o n}$ & $\dot{W}_{c y c l e, h i g h}$ & $Q_{\text {in,low }}$ & $Q_{\text {in,on }}$ & $Q_{\text {in,high }}$ & $\dot{\mathrm{W}}_{\text {cooling,low }}$ & $\dot{W}_{\text {cooling,on }}$ & $\dot{\mathbf{W}}_{\text {cooling,high }}$ & $\dot{m}_{w, \text { cooling,low }}$ & $\dot{m}_{w, \text { coolingon }}$ & $\dot{m}_{w, \text { cooling, high }}$ \\
\hline 700 & 0.13893 & 0.85703 & 0.912 & 0.16588 & 0.91658 & 0.97042 & 0.088139 & 1 & 0.90031 & 0.16588 & 0.91658 & 0.97042 \\
\hline 705 & 0.14061 & 0.86785 & 0.92333 & 0.1666 & 0.92329 & 0.97745 & 0.091209 & 1 & 0.90031 & 0.1666 & 0.92329 & 0.97745 \\
\hline 710 & 0.14236 & 0.87873 & 0.9345 & 0.16742 & 0.9299 & 0.98448 & 0.097024 & 1 & 0.90031 & 0.16742 & 0.9299 & 0.98448 \\
\hline 725 & 0.1474 & 0.91036 & 0.96783 & 0.16975 & 0.94992 & 1.0052 & 0.1124 & 1 & 0.90031 & 0.16975 & 0.94992 & 1.0052 \\
\hline 730 & 0.14859 & 0.9238 & 0.97924 & 0.17056 & 0.95517 & 1.0121 & 0.11938 & 1 & 0.90031 & 0.17056 & 0.95517 & 1.0121 \\
\hline 735 & 0.14928 & 0.93018 & 0.98974 & 0.1709 & 0.96188 & 1.0186 & 0.11938 & 1 & 0.90031 & 0.1709 & 0.96188 & 1.0186 \\
\hline 755 & 0.15637 & 0.96885 & 1.0346 & 0.17451 & 0.98478 & 1.0437 & 0.14463 & 1 & 0.90031 & 0.17451 & 0.98478 & 1.0437 \\
\hline 760 & 0.15821 & 0.9818 & 1.0413 & 0.17511 & 0.98953 & 1.0505 & 0.15914 & 1 & 0.90031 & 0.17511 & 0.98953 & 1.0505 \\
\hline 765 & 0.1597 & 0.98829 & 1.0541 & 0.17586 & 0.99594 & 1.0552 & 0.16548 & 1 & 0.90031 & 0.17586 & 0.99594 & 1.0552 \\
\hline 770 & 0.16117 & 1 & 1.0608 & 0.17659 & 1 & 1.062 & 0.1725 & 1 & 0.90031 & 0.17659 & 1 & 1.062 \\
\hline 775 & 0.16246 & 1.007 & 1.0731 & 0.17729 & 1.0065 & 1.0666 & 0.17775 & 1 & 0.90031 & 0.17729 & 1.0065 & 1.0666 \\
\hline 780 & 0.16361 & 1.0178 & 1.08 & 0.1778 & 1.01 & 1.0736 & 0.17775 & 1 & 0.90031 & 0.1778 & 1.01 & 1.0736 \\
\hline 785 & 0.16461 & 1.025 & 1.0929 & 0.17828 & 1.0167 & 1.0783 & 0.17775 & 1 & 0.90031 & 0.17828 & 1.0167 & 1.0783 \\
\hline
\end{tabular}


Table A5. Performance as a function of HTF mass flow rate (MOD2) table for Partial Cooling cycle. "Low", "On" and "High" respectively refer to the three values of ambient temperature employed: 5, 15 and $40^{\circ} \mathrm{C}$.

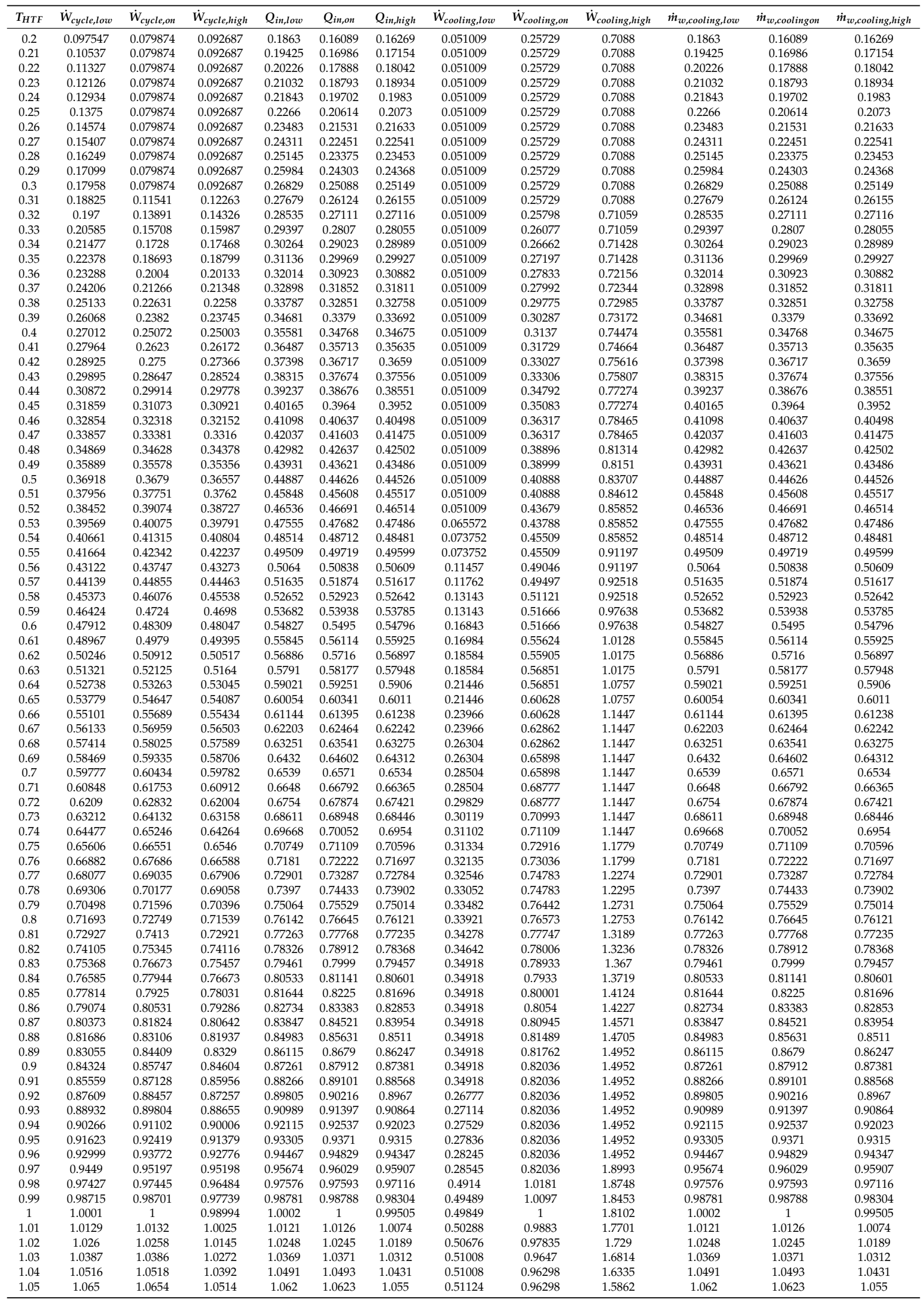


Table A6. Performance as a function of ambient temperature (MOD3) table for Partial Cooling cycle. "Low", "On" and "High" respectively refer to the three values of molten salt (hot) temperature levels employed: 700,770 and $800{ }^{\circ} \mathrm{C}$.

\begin{tabular}{|c|c|c|c|c|c|c|c|c|c|c|c|c|}
\hline$T_{H T F}$ & $\dot{\mathrm{W}}_{\text {cycle, low }}$ & $\dot{\mathbf{W}}_{c y c l e, o n}$ & $\dot{\mathbf{W}}_{c y c l e, h i g h}$ & $Q_{\text {in,low }}$ & $Q_{i n, o n}$ & $Q_{\text {in,high }}$ & $\dot{\mathrm{W}}_{\text {cooling,low }}$ & $\dot{\mathbf{W}}_{\text {cooling,on }}$ & $\dot{\mathbf{W}}_{\text {cooling,high }}$ & $\dot{m}_{w, \text { cooling, low }}$ & $\dot{m}_{w, \text { coolingon }}$ & $\dot{m}_{w, \text { cooling,higl }}$ \\
\hline 5 & 0.87197 & 1.0106 & 1.051 & 0.92305 & 1.0058 & 1.0289 & 0.52313 & 0.54897 & 0.5307 & 0.92305 & 1.0058 & 1.0289 \\
\hline 6.25 & 0.86862 & 1.0157 & 1.056 & 0.92122 & 1.0057 & 1.0287 & 0.55291 & 0.58798 & 0.56835 & 0.92122 & 1.0057 & 1.0287 \\
\hline 7.5 & 0.86503 & 1.0139 & 1.0541 & 0.91958 & 1.0046 & 1.0277 & 0.59877 & 0.6321 & 0.6104 & 0.91958 & 1.0046 & 1.0277 \\
\hline 11.25 & 0.86147 & 1.003 & 1.0424 & 0.91735 & 1.0006 & 1.0236 & 0.77223 & 0.78855 & 0.75934 & 0.91735 & 1.0006 & 1.0236 \\
\hline 12.5 & 0.86147 & 0.99992 & 1.0401 & 0.91736 & 0.99998 & 1.0231 & 0.8467 & 0.85827 & 0.82408 & 0.91736 & 0.99998 & 1.0231 \\
\hline 13.75 & 0.8613 & 1.0002 & 1.0401 & 0.91736 & 0.99999 & 1.0231 & 0.92843 & 0.92682 & 0.88976 & 0.91736 & 0.99999 & 1.0231 \\
\hline 18.75 & 0.86189 & 1.0005 & 1.0402 & 0.9174 & 1 & 1.0231 & 1.3482 & 1.2329 & 1.1821 & 0.9174 & 1 & 1.0231 \\
\hline 20 & 0.86152 & 1.0001 & 1.0403 & 0.9174 & 1 & 1.0231 & 1.454 & 1.3145 & 1.2621 & 0.9174 & 1 & 1.0231 \\
\hline 21.25 & 0.86232 & 1.0007 & 1.0405 & 0.91743 & 1.0001 & 1.0231 & 1.5404 & 1.3904 & 1.3425 & 0.91743 & 1.0001 & 1.0231 \\
\hline 22.5 & 0.86182 & 1.0003 & 1.0407 & 0.91741 & 1 & 1.0232 & 1.6166 & 1.4649 & 1.4205 & 0.91741 & 1 & 1.0232 \\
\hline 23.75 & 0.86155 & 1.0006 & 1.0409 & 0.91741 & 1.0001 & 1.0231 & 1.6825 & 1.5306 & 1.4934 & 0.91741 & 1.0001 & 1.0231 \\
\hline 25 & 0.86202 & 1.0008 & 1.0405 & 0.91745 & 1.0001 & 1.0231 & 1.7397 & 1.5917 & 1.5614 & 0.91745 & 1.0001 & 1.0231 \\
\hline 26.25 & 0.86236 & 1.0005 & 1.0402 & 0.91746 & 1.0001 & 1.0231 & 1.7907 & 1.6479 & 1.6216 & 0.91746 & 1.0001 & 1.0231 \\
\hline 34 & 0.86263 & 1.0008 & 1.0412 & 0.9175 & 1.0001 & 1.0232 & 2.0074 & 1.8832 & 1.8705 & 0.9175 & 1.0001 & 1.0232 \\
\hline 35 & 0.86232 & 1.0009 & 1.0408 & 0.91749 & 1.0001 & 1.0232 & 2.0248 & 1.901 & 1.8904 & 0.91749 & 1.0001 & 1.0232 \\
\hline 36 & 0.86216 & 1.0007 & 1.0407 & 0.91749 & 1.0001 & 1.0232 & 2.0396 & 1.9177 & 1.907 & 0.91749 & 1.0001 & 1.0232 \\
\hline 37 & 0.8628 & 1.0013 & 1.0413 & 0.91751 & 1.0001 & 1.0232 & 2.051 & 1.929 & 1.9193 & 0.91751 & 1.0001 & 1.0232 \\
\hline 38 & 0.86247 & 1.0002 & 1.041 & 0.91748 & 1.0001 & 1.0232 & 2.0601 & 1.9414 & 1.9297 & 0.91748 & 1.0001 & 1.0232 \\
\hline 39 & 0.8622 & 1.0017 & 1.0407 & 0.91747 & 1.0003 & 1.0232 & 2.0671 & 1.9485 & 1.938 & 0.91747 & 1.0003 & 1.0232 \\
\hline 40 & 0.86193 & 1.0016 & 1.0404 & 0.91748 & 1.0003 & 1.0232 & 2.0719 & 1.951 & 1.9433 & 0.91748 & 1.0003 & 1.0232 \\
\hline
\end{tabular}

\section{References}

1. Office of Energy Efficiency \& Renewable Energy-The Sunshot Iniciative. Available online: https: / / www. energy.gov / eere/solar/sunshot-initiative (accessed on 15 March 2019).

2. Manzolini, G.; Binotti, M.; Bonalumi, D.; Invernizzi, C.; Iora, P. CO2 mixtures as innovative working fluid in power cycles applied to solar plants. Techno-economic assessment. Solar Energy 2019, 181, 530-544. [CrossRef]

3. Binotti, M.; Di Marcoberardino, G.; Iora, P.; Invernizzi, C.M.; Manzolini, G. Supercritical carbon dioxide/alternative fluids blends for efficiency upgrade of solar power plant. In Proceedings of the 3rd European Conference on Supercritical $\mathrm{CO}_{2}\left(\mathrm{sCO}_{2}\right)$ Power Systems 2019, Paris, France, 19-20 September 2019; pp. 222-229.

4. Crespi, F.; Gavagnin, G.; Sánchez, D.; Martínez, G. Supercritical Carbon Dioxide Cycles for Power Generation: A Review. Appl. Energy 2017, 195, 152-183. [CrossRef]

5. Sulzer, G. Verfahren zur Erzeugung von Arbeit aus Warme. Swiss Patent 1950, 269599.

6. Angelino, G. Carbon Dioxide Condensation Cycles for Power Production. J. Eng. Power 1968, 90, $287-295$. [CrossRef]

7. Feher, E. The supercritical thermodynamic power cycle. Energy Conv. Manag. 1968, 8, 85-90. [CrossRef]

8. Crespi, F.; Gavagnin, G.; Sánchez, D.; Martínez, G. Analysis of the Thermodynamic Potential of Supercritical Carbon Dioxide Cycles: A Systematic Approach. J. Eng. Gas Turb. Power 2017, 140, 051701. [CrossRef]

9. Crespi, F.; Sánchez, D.; Rodríguez, J.; Gavagnin, G. Fundamental Thermo-Economic Approach to Selecting $\mathrm{sCO}_{2}$ Power Cycles for CSP Applications. Energy Procedia 2017, 129, 963-970. [CrossRef]

10. Crespi, F.; Sánchez, D.; Sánchez, T.; Martínez, G.S. Capital Cost Assessment of Concentrated Solar Power Plants Based on Supercritical Carbon Dioxide Power Cycles. J. Eng. Gas Turb. Power 2019, 141. [CrossRef]

11. Crespi, F.; Sánchez, D.; Sánchez-Lencero, T.; Martínez, G.; Muñoz, A. Off-design operation of Supercritical Carbon Dioxide Power Cycles in Concentrated Solar Power plants. Appl. Thermal Eng. 2020, in press.

12. Various. Report on Best Available Technologies (BAT) for Central Receiver Systems; Technical Report; Abengoa Energia, University of Seville: Seville, Spain, 2019.

13. Martin, M. Techno-Economic Assessment of Concentrated Solar Power Tower Plants Integrating Pressurised Air Rceivers and Gas Turbines. Ph.D. Thesis, University of Seville, Seville, Spain, 2018. (In Spanish)

14. Williams, D. Assessment of Candidate Molten Salt Coolants for the NGNP/NHI Heat-Transfer Loop; Technical Report; Oak Ridge National Lab (ORNL): Oak Ridge, TN, USA, 2006. 
15. Mehos, M.; Turchi, C.; Vidal, J.; Wagner, M.; Ma, Z.; Ho, C.; Kolb, W.; Andraka, C.; Kruizenga, A. Concentrating Solar Power Gen3 Demonstration Roadmap; Technical Report; National Renewable Energy Lab (NREL): Golden, CO, USA, 2017.

16. Yoon, S.; Sabharwall, P.; Kim, E. Analytical Study on Thermal and Mechanical Design of Printed Circuit Heat Exchanger; Technical Report; Idaho Nation Laboratory: Idaho Falls, ID, USA, 2013.

17. Prieto, C.; Fereres, S.; Ruiz-Cabañas, F.J.; Rodriguez-Sanchez, A.; Montero, C. Carbonate molten salt solar thermal pilot facility: Plant design, commissioning and operation up to $700{ }^{\circ} \mathrm{C}$. Renew. Energy 2020, 151, 528-541. [CrossRef]

18. Turchi, C.S.; Ma, Z.; Neises, T.W.; Wagner, M.J. Thermodynamic study of advanced supercritical carbon dioxide power cycles for concentrating solar power systems. J. Solar Energy Eng. 2013, 135, 041007.

19. Dyreby, J.; Klein, S.; Nellis, G.; Reindl, D. Design considerations for supercritical carbon dioxide Brayton cycles with recompression. J. Eng. Gas Turb. Power 2014, 136, 101701. [CrossRef]

20. Silvestri, G. Eddystone Station, 325 MW Generating Unit, A Brief History; ASME: Philadelphia, PA, USA, 2003.

21. Weiland, N.T.; Lance, B.W.; Pidaparti, S.R. $\mathrm{sCO}_{2}$ Power Cycle Component Cost Correlations From DOE Data Spanning Multiple Scales and Applications. In Proceedings of the ASME Turbo Expo 2019: Turbomachinery Technical Conference and Exposition, Phoenix, AZ, USA, 17-21 June 2019.

22. Carlson, M.D.; Middleton, B.M.; Ho, C.K. Techno-economic comparison of solar-driven $\mathrm{SCO}_{2} \mathrm{Brayton}$ cycles using component cost models baselined with vendor data and estimates. In Proceedings of the ASME 2017-11th International Conference on Energy Sustainability Collocated with the ASME 2017 Power Conference Joint With ICOPE-17, the ASME 2017 15th International Conference on Fuel Cell Science, Engineering and Technology, and the ASME 2017 Nuclear Forum (Digital Collection); American Society of Mechanical Engineers (ASME): New York, NY, USA, 2017.

23. IRENA. Renewable Power Generation Costs in 2018; International Renewable Energy Agency: Abu Dhabi, UAE, 2019.

24. Allam, R.; Fetvedt, J.; Forrest, B.; Freed, D. The Oxy-Fuel, Supercritical $\mathrm{CO}_{2}$ Allam Cycle: New Cycle Developments to Produce Even Lower-Cost Electricity From Fossil Fuels Without Atmospheric Emissions. In ASME Turbo Expo 2014: Turbine Technical Conference and Exposition; ASME: New York, NY, USA, 2014.

25. Kulhánek, M.; Dostal, V. Thermodynamic analysis and comparison of supercritical carbon dioxide cycles. In Proceedings of the Supercritical $\mathrm{CO}_{2}$ Power Cycle Symposium, Boulder, CO, USA, 24-25 May 2011; pp. 1-7.

26. Neises, T.; Turchi, C. Supercritical $\mathrm{CO}_{2}$ Power Cycles: Design Considerations for Concentrating Solar Power. In Proceedings of the 4 th Supercritical $\mathrm{CO}_{2}$ Power Cycles Symposium, Pittsburgh, PA, USA, 9-10 September 2014; Volume 2, pp. 9-10.

27. Crespi, F. Thermo-Economic Assessment of Supercritical $\mathrm{CO}_{2}$ Power Cycles for Concentrated Solar Power Plants. Ph.D. Thesis, Unviersity of Seville, Seville, Spain, 2019.

28. Schmitt, J.; Wilkes, J.; Allison, T.; Bennett, J.; Wygant, K.; Pelton, R. Lowering the Levelized Cost of Electricity of a Concentrating Solar Power Tower With a Supercritical Carbon Dioxide Power Cycle. In ASME Turbo Expo 2017: Turbomachinery Technical Conference and Exposition (Digital Collection); American Society of Mechanical Engineers (ASME): New York, NY, USA, 2017.

29. Ho, C.; Mehos, M.; Turchi, C.; Wagner, M. Probabilistic Analysis of Power Tower Systems to Achieve Sunshot Goals. Energy Procedia 2014, 49, 1410-1419. [CrossRef]

30. Crespi, F.; Sánchez, D.; Hoopes, K.; Choi, B.; Kuek, N. The Conductance Ratio Method for Off-Design Heat Exchanger Modeling and its Impact on an $\mathrm{sCO}_{2}$ Recompression Cycle. In ASME Turbo Expo 2019: Turbomachinery Technical Conference and Exposition (Digital Collection); American Society of Mechanical Engineers (ASME): New York, NY, USA, 2019.

31. Sánchez, D.; Bortkiewicz, A.; Rodr'íguez, J.; Martínez, G.; Gavagnin, G.; Sánchez, T. A methodology to identify potential markets for small-scale solar thermal power generators. Appl. Energy 2016, 169, 287-300. [CrossRef]

(C) 2020 by the authors. Licensee MDPI, Basel, Switzerland. This article is an open access article distributed under the terms and conditions of the Creative Commons Attribution (CC BY) license (http:/ / creativecommons.org/licenses/by/4.0/). 